HUMAN TRAFFICKING SURVIVORS, AFTER CARE SERVICES, AND INSTITUTIONAL BETRAYAL: A QUALITATIVE PERSPECTIVE ON THE EFFECTIVENESS OF A VICTIM ADVOCACY PROGRAM

A Dissertation
presented to
the Faculty of the Graduate School
at the University of Missouri-
Columbia
In Partial Fulfillment
of the Requirements for the Degree
Doctor of Educational Leadership and Policy
Analysis
by

Jodi L. Williams

March, 2017 
(C) Copyright by Jodi L. Williams, 2017

All Rights Reserved 
The undersigned, appointed by the dean of the Graduate School, have examined the dissertation entitled

\section{HUMAN TRAFFICKING SURVIVORS, AFTER CARE SERVICES, AND INSTITUTIONAL BETRAYAL: A QUALITATIVE PERSPECTIVE ON THE EFFECTIVENESS OF A VICTIM ADVOCACY PROGRAM}

presented by Jodi L. Williams, a candidate for the degree of doctor of Educational Leadership and Policy Analysis, and hereby certify that, in their opinion, it is worthy of acceptance.

Dr. David Stader

Dr. Paul Watkins

Dr. William Bratberg

Dr. Sharon Gunn 


\section{Dedications}

This work is dedicated to my family. Thank you to my parents for always believing in me and showing me unconditional love throughout my life. Thank you to my husband, Dustin, for encouraging me every step of the way and making every day better. Your love and support make all the difference and I'm glad I get to do life with you. Gabby deserves credit, too, for the happy face and wagging tail that greeted me at the end of some incredibly long days. And the newest member of our family, who won't be making an official appearance until September but showed up just in time to be part of the journey. I couldn't have done it without each of you. 


\section{Acknowledgements}

Dr. David Stader, thank you for recognizing my capabilities and supporting me throughout the doctoral process. Your encouragement and guidance as my advisor made this a successful and enjoyable journey.

I would also like to thank Dr. Paul Watkins, Dr. Sharon Gunn, and Dr. William Bratberg for serving on my dissertation committee. I greatly appreciate the time, advice, and experience you each shared with me.

Dr. Erin Fluegge, thank you for sparking my interest in research and writing. You inspire me to want more and go after it, in all walks of life. 


\section{TABLE OF CONTENTS}

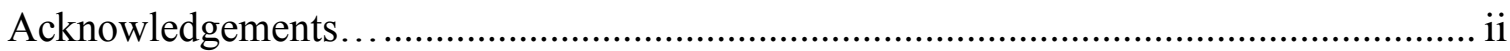

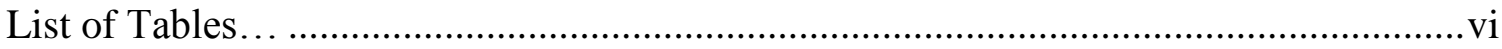

List of Abbreviations..............................................................................................

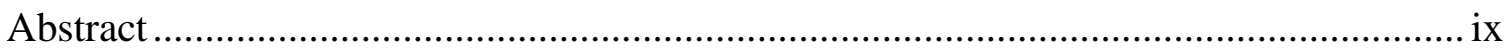

Chapter

1. Introduction to the Dissertation-in-Practice ....................................................... 1

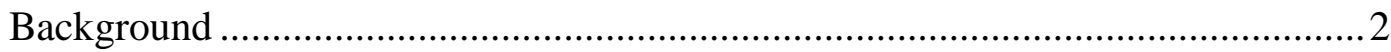

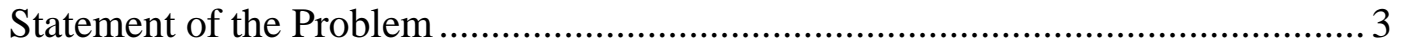

Problem of practice

Existing gap in the literature

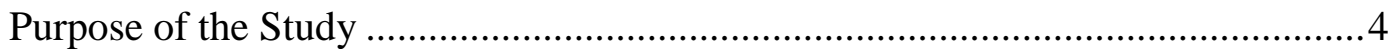

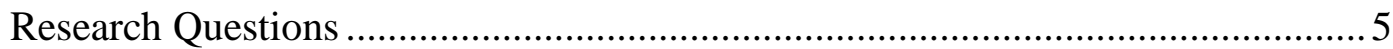

Conceptual/Theoretical Framework .................................................................... 5

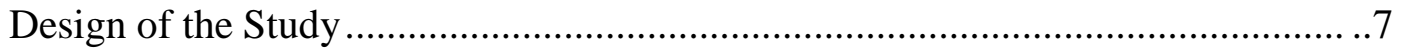

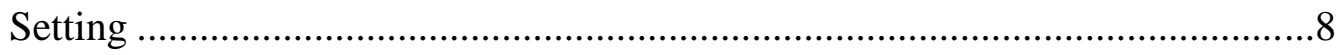

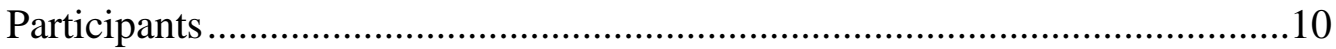

Data Collection Tools ....................................................................................11

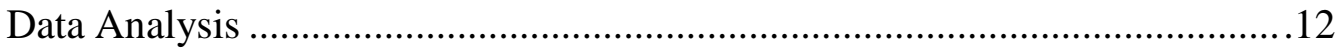

Limitations, Assumptions, and Design Controls................................................13

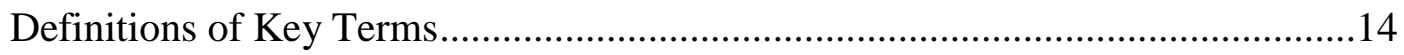

Significance of the Study .....................................................................................17

Scholarship

Practice 


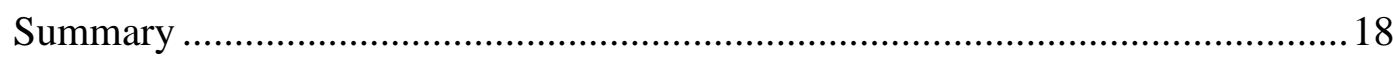

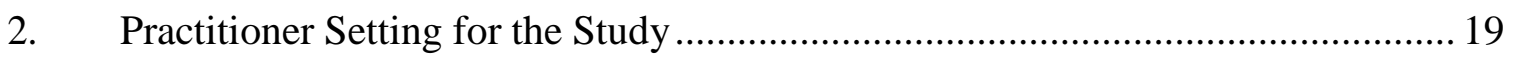

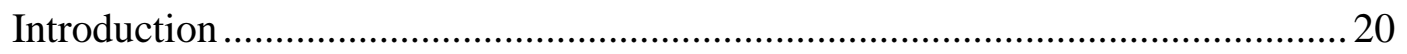

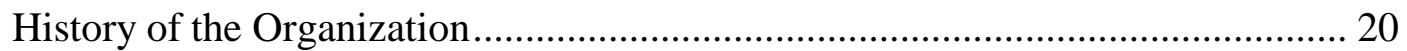

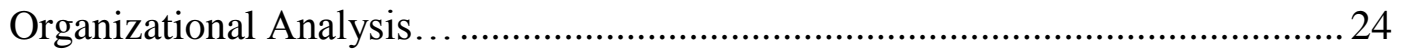

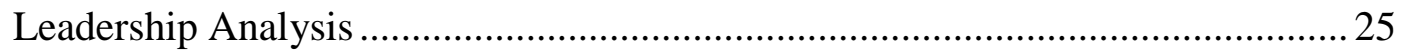

Implications for Research in the Practitioner Setting...........................................2

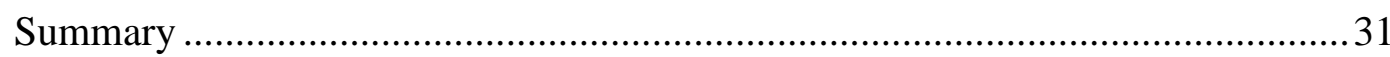

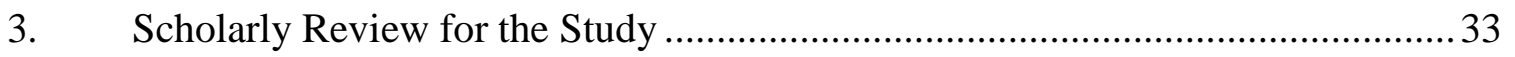

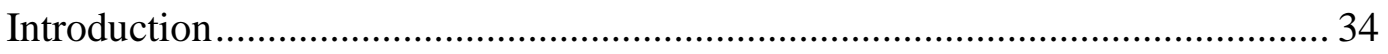

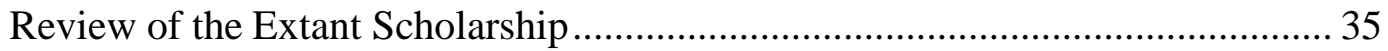

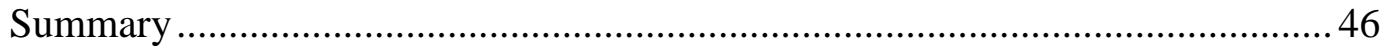

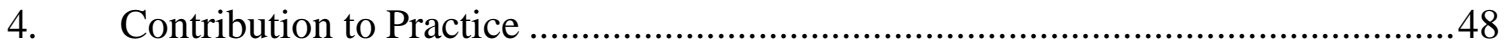

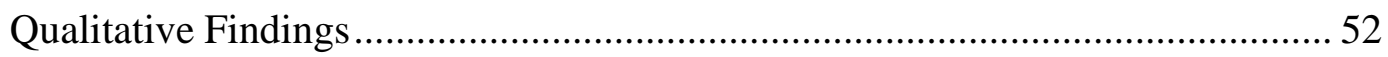

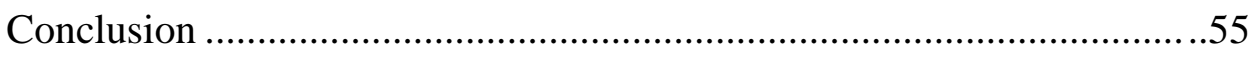

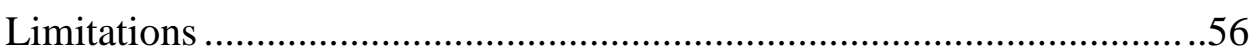

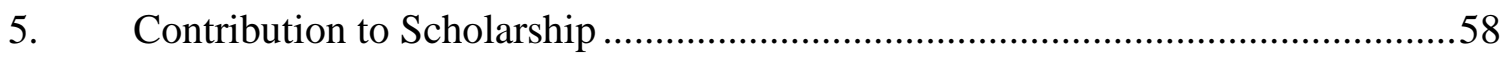

Submission-Ready Journal Article ………………………......................62

6. Scholarly Practitioner Reflection........................................... 99

How has the dissertation influenced my practice as an educational leader?

How has the dissertation process influenced me as a scholar?

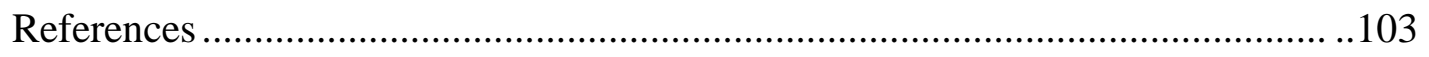

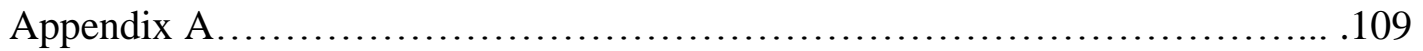


Appendix B.................................................... 111

Appendix C.......................................................... 113

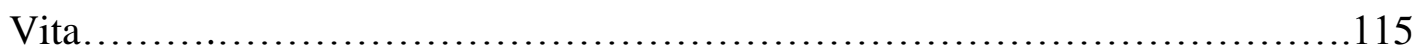


List of Tables

Table 1: Institutional Betrayal Experienced by Human Trafficking Survivors 


\section{List of Abbreviations}

CVU: Crime Victims Unit

GEMS: Girls Education and Mentoring Services

MoCVSU: Missouri Crime Victim Services Unit

MSA: Missouri Sheriffs' Association

MSATA: Missouri Sheriffs' Association and Training Academy

PTSD: Post-Traumatic Stress Disorder

TVPA: Trafficking Victims Protection Act 


\begin{abstract}
This qualitative study was designed to evaluate the effectiveness of the Missouri Sheriff's Association Victim Advocacy Program in rehabilitating human trafficking survivors. The conceptual framework for this study includes betrayal trauma theory and, more specifically, institutional betrayal. Betrayal trauma theory expounds on the posttraumatic effects of trauma on persons when betrayal occurs in an attachment relationship; the concept of institutional betrayal builds on this theory and outlines the significance of an institution betraying an individual who trusts or depends upon that institution just as they would another person (Parnitzke, Smith, \& Freyd, 2014).

Data collected from the one-on-one interviews will provide a more thorough understanding of human trafficking survivors and will be coded for consistencies and emerging themes in terms of trauma, betrayal, and after care. The aftermath survivors experience will be examined through the lens of institutional betrayal, specifically focusing on the services provided by the Victim Advocacy Program. This data will increase understanding of human trafficking, the impact of secondary trauma of betrayal, and why effective after care services are crucial.
\end{abstract}


SECTION ONE

INTRODUCTION TO DISSERTATION 


\section{Introduction to the Background of the Study}

Although there is a shared consensus on the cruelty and inhumanity of human trafficking, the question of what to do about it is proving difficult to answer. There is a lot of talk about how to prevent it and much emphasis is placed on increasing awareness, but what about when that does not work? Modern day slavery is happening; some of it is being prevented, but certainly not all. What about those individuals? Survivors are in need of effective after care services and programs in order to help overcome the trauma they have experienced and successfully rebuild their lives.

After care services are just as, if not more, important than prevention as human trafficking is increasingly happening across the United States, including in Missouri and the neighboring states. Although recruitment of victims and selling of sexual services can easily take place anywhere in America, smaller cities in the Midwest have been identified as high recruitment areas where traffickers manipulate and force youth into trafficking, and move them around to other cities throughout the country to further profit from the inhumane life of slavery they have inflicted upon them (Williamson and Prior, 2009). Prevention campaigns and awareness are not going to help once someone has fallen victim to trafficking.

Preventative measures alone are simply not enough to tackle this escalating crisis. Focusing on human trafficking specifically through the lens of institutional betrayal helps illustrate the emotional and mental aftermath that survivors experience and how betrayal by trusted institutions may exacerbate these traumatic effects, helping demonstrate why effective after care programs are important. Past literature also helps shed light on human trafficking and why this topic is important, as well as why more research in the area of after care services and survivor rehabilitation is needed. 


\section{Statement of Problem}

Human trafficking is a growing problem nationwide with no clear cut solutions. The importance of increasing awareness and educating people about preventative measures is frequently discussed in articles. However, there is limited research on the specific topic of after care and survivor programs, as well as other service provisions, available to those who have been victims of trafficking.

Preventative measures are important, but they are not going to help human trafficking survivors any more than a bulletproof vest is going to help someone who has already been shot. It is necessary to know how to deal with something when it happens, not just how to help prevent it. Additionally, there is little research on the effectiveness of existing after care programs. Have these programs actually helped survivors? How? What can be done to improve them? These are all important factors that need to be studied in order to provide the best after care services to survivors.

There is also little to no research examining human trafficking through the lens of betrayal trauma theory, specifically institutional betrayal. Researching and describing the lived experiences of survivors themselves through this specific lens creates a clearer picture of what being a human trafficking survivor entails, and the betrayal that some may unfortunately experience at the hands of those entrusted to help. Liberation from trafficking is only the beginning for a survivor; recovery is a long road and often those responsible for providing much needed support to survivors do just the opposite. Research has shown that institutions can cause additional harm to assault survivors (Smith \& Freyd, 2013). When a trafficking survivor is betrayed by the people and institutions that have entrusted to help, an already traumatic 
experience is considerably worsened, further demonstrating the need for effective after care services.

\section{Purpose}

Focusing on trafficking survivors and the psychological trauma they experience will help exemplify what is meant by human trafficking and why effective survivor programs are necessary. While preventative measures are important, more needs to be done for those that prevention methods are not going to help; the survivors. After care services are vital to assisting human trafficking survivors through the aftermath of this traumatic ordeal and helping them rebuild their lives. Moreover, studying this trauma specifically through the institutional betrayal lens demonstrates the importance of effective after care services, as inadequate help only worsens traumatic effects. For the purpose of this study, there is a difference between the terms 'victim' and 'survivor'. Anyone who has been trafficked has been a victim, and the ones trapped in a trafficking situation remain victims, and will be referred to as such. The term survivor refers to those who have been liberated and denotes life after trafficking.

Looking at the issue of human trafficking through the lens of institutional betrayal will help illustrate what survivors go through and the aftermath once they are free, as well as why rehabilitation is crucial. Not only should these programs exist, measures should be taken to ensure survivor's needs are being met in the best way possible and that institutional betrayal is not occurring. Examining the challenges survivors face through this lens as they rebuild their lives and what part after care services have played in their reintegration can help determine how effective these types of programs are, as well as how they can be improved upon. Additionally, this study may help other, similar advocacy programs to review and improve their current after care services in order to better serve human trafficking survivors. 


\section{Research Questions}

The research questions guiding this study are:

1. How do human trafficking survivors perceive after care services?

2. How do Victim Advocates perceive after care services?

\section{Conceptual/Theoretical Framework}

Betrayal trauma theory explains the unique posttraumatic aftereffects of traumatic experiences that involve betrayal as stemming from the maintenance of attachment relationships necessary for survival (Parnitzke, Smith, \& Freyd, 2013). Building on this theory is the concept of institutional betrayal. Institutions often illicit similar trust and dependency from their members that is common in interpersonal relationships, meaning an individual can be betrayed by an institution just as they can by another person. Simply put, institutional betrayal occurs when an institution causes harm to an individual who trusts or depends on that institution (Parnitzke, Smith, \& Freyd, 2014). For instance, when law enforcement incorrectly view human trafficking victims as perpetrators of crimes, such as prostitution, and when cases are not dismissed or diverted but sent deeper into the justice system, this is institutional betrayal and the cost is twofold: the traffickers are shielded from accountability and the real crime and trauma on the victim is not addressed (Williams, 2015). Further damage is done to victims when law enforcement officials and service providers fail to help them or directly do more harm. Human trafficking victims can be betrayed in a myriad of ways, intensifying traumatic experiences.

Institutional betrayal can include acts of commission, such as covering up information and having insensitive responses to disclosures of trauma (e.g. misreporting and victim blaming) or failing to prevent mistreatment (e.g. withholding services and not communicating victims legal options) (Smith, Gomez, \& Freyd, 2014). Research has framed institutional factors as 
contributing to victim's existing traumatic stress, such as insufficient legal protection and services following domestic violence (Campbell, 2006; Campbell \& Raja, 2005; Carr, Dooley, Fitzpatrick, Flanagan-Howard, Tierney, \& Egan, 2010; McDonald, Beaulie, Harbison, Hirst, Lowenstein, Podnieks, \& Wahl, 2012). Campbell (2006) noted, "When victims reach out for help, they place a great deal of trust in the legal, medical, and mental health systems as they risk disbelief, blame, and refusals of help" (p. 703). When human trafficking victims reach out to law enforcement or disclose the truth to a service provider, they trust an institution enough to risk the real and imagined threats from traffickers in order to get help; but all too often, they do not receive it. Some victims have attempted to escape while in medical facilities, only to have health care providers disbelieve them entirely or discount their claims (Hodge, 2014). Similarly, police officers have rejected trafficking claims as false and some have sent victims back home with their trafficker following the "dispute" (p. 115).

Research indicates that institutions such as judicial systems, hospitals, and schools have the potential to either worsen posttraumatic outcomes or become sources of support and healing (Campbell, 2006; Healy 2012), supporting the concept of institutional betrayal. This deep lack of validation from an institution mirrors a mechanism thought to predict the development of posttraumatic responses (Smith \& Freyd, 2014). In line with this, institutional betrayal leading up to or following a sexual assault is associated with more posttraumatic difficulties such as depression, PTSD symptoms, and lower self-esteem (Smith, Gomez, \& Freyd, 2014). Consistent with betrayal trauma theory, women who experienced institutional betrayal also had severe posttraumatic symptoms; they exhibited increased levels of anxiety, trauma specific sexual symptoms, dissociation, and problematic sexual functioning (Smith \& Freyd, 2013). Additionally, even when controlling for other sexual and physical abuse, abuse in an institutional 
setting was predictive of unique psychological distress and physical difficulties (Carr, Dooley, Fitzpatrick, Flanagan-Howard, Tierney, \& Egan, 2010). This pattern of results may offer an explanation for the increased difficulties observed in victims following abuse in cases of violence which involve failed attempts to seek help from law enforcement (Smith \& Freyd, 2013). Therefore, it can logically be inferred that institutional betrayal exacerbates what is already a traumatic experience (p. 123).

It is not surprising human trafficking victims feel re-victimized during the long process of investigation and prosecution. They are often criminalized and basic needs are not met due to the cumbersome policy requirements to access after care services (Logan, Walker, \& Hunt, 2009). Law enforcement, health care professionals, and the judicial system itself often betray these victims and the trauma associated with this level of institutional betrayal has serious repercussions. Examining human trafficking through this theoretical lens not only helps illustrate the effects of human trafficking and the secondary trauma associated with institutional betrayal, but also the importance of having high functioning after care services in place for survivors to rely on.

\section{Design}

This research study will be qualitative in nature. One-on-one interviewing will ensure the individual human trafficking survivors and victim advocates experiences weigh heavily on the results of data collection. Qualitative data will strengthen the study by effectively conveying each of the survivor's perspectives through detailed descriptions relevant to identifying trauma, whether or not institutional betrayal applies, implications of this secondary betrayal (if applicable), quality of after care services received, and what improvements need to be made to 
the program, as well as the advocate's perspectives. As a result of the researcher's connection to the Victim Advocacy Program, personal bias has been acknowledged.

Internal validity, the credibility of the results, will be established by triangulation of the data through both multiple methods of data collection and multiple data sources (Merriam and Tisdell, 2016). The researcher will check what is said during the one-on-one interview with each survivor against the observations and documents previously obtained by the Missouri Sheriff's Association, as well as compare the findings to past data collected by interviewing the Crime Victim's Unit Case Manager. By triangulating this information with the qualitative data collected to see if it correlates, the researcher is working to increase the credibility of this research study. External validity, or reliability, is based on the assumption that research can be replicated (Merriam and Tisdell, 2016). However, this is problematic in the social sciences as human behavior is not static; it is considered even more problematic in qualitative research. The research findings of this study may not be an accurate representation of other programs in other areas as it is specifically evaluating the MSA Victim Advocacy Program in the state of Missouri and therefore may not be easily replicated.

\section{Setting}

A qualitative study will be conducted using data collected from human trafficking survivors and victim advocates currently involved with the Missouri Sheriffs' Association Victim Advocacy Program in Jefferson City, Missouri. This program is a part of the Crime Victims Unit (CVU) and also serves victims of other violent crimes, such as domestic abuse and sexual assault. There are plans to develop a division of the Advocacy Program strictly for human trafficking survivors, but this has proven to be a difficult and time consuming process. At the time of this study, there is not a set date for the human trafficking division to start. 


\section{Missouri Sheriffs' Association}

Founded in 1945, the Missouri Sheriffs' Association (MSA) is a non-profit organization supporting the Office of Sheriff and the Constitution ("MSA", 2015). It is home to the Missouri Sheriffs' Association Training Academy (MSATA) and offers basic training to officers, as well as grant funded trainings and continuing education trainings. The MSA has 10 full-time staff members and four adjunct staff members; these 14 employees make up the Crime Victims Unit, the Training Academy, and also include office, grounds, and maintenance staff. The MSA also has an eight-member Board of Directors, exclusively made up of Sheriffs from different counties in Missouri.

\section{Crime Victims Unit and Victim Advocacy Program}

The Crime Victims Unit (CVU) of the Missouri Sheriffs' Association exists to be an advocate for victims as they go through the criminal justice system. It was developed in order to aid law enforcement and assist victims by connecting them with caring resources in the community; from the first encounter with law enforcement, and through every stage of the criminal justice process, the CVU strives to make the experience as positive as possible ("MSA", 2015). As part of the CVU, Advocates in the Victim Advocacy Program are responsible for assisting Missouri law enforcement with providing enhanced victim services in the following ways: 1) Provide a response to the emotional and physical needs of crime victims, 2) assist primary and secondary victims and help stabilize their lives after victimization, 3) help victims understand and participate in the criminal justice process, and 4) provide victims with a measure of safety (MSA CVU Program Services, Policies, \& Procedures, 2013). Advocates also provide packets which include additional information, such as subsequent steps of case processing and handling, what to do if threatened or intimidated, and contacts for future crises or emergencies, 
just to name a few examples ("MSA", 2015). This information can also be found on the MSA CVU website, along with a Victim Services link which specifically details the services Advocates assist with, as well as a Frequently Asked Questions link ("MSA", 2015).

This particular Victim Advocacy Program was chosen by the researcher because of its close proximity and the willingness of the Victim Advocate Case Manager, the Human Trafficking Specialist, and the survivors currently involved in the program to participate in the research study. This program also has close ties with law enforcement officials, another important segment of after care services and possible institutional betrayal. All interviews will be administered at the Missouri Sheriffs' Association Training Academy in Jefferson City.

\section{Participants}

This research study will potentially utilize a sample of five to seven human trafficking survivors, aged 18 or older, currently involved with the MSA Victim Advocacy Program. A sample of five to seven Advocates will also be utilized. This sample was chosen to illustrate what human trafficking survivors experience, the associated trauma, the presence and implications of institutional betrayal, and the effectiveness of the advocacy after care program, as well as the Advocates perception of these services. This method of selecting a sample from which the most can be learned is known as purposeful sampling (Merriam, 2009). Potential participants will be contacted through the CVU of the MSA. The Victim Advocate Case Manager will assist in the selection of survivors and advocates to participate in the study. The survivors and advocates will then be asked, confidentially and individually, if they would like to participate in the study. They are free to accept or decline without repercussion.

All of the participants will be provided with an informed consent letter explaining the purpose of the study and that participation is voluntary and anonymous. Formal consent forms 
will meet approval of the IRB Committee of the University of Missouri - Columbia and Southeast Missouri State University. Qualitative data will not be collected without dated letters of informed consent from all participants (Merriam, 2009). Interview requests will be voluntary, with each participant having the option to withdraw at any time without repercussions (Krueger \& Casey, 2009). To maintain privacy, all collected information will be kept confidential (Creswell, 2012; Merriam, 2009). The researcher will not record names, social security numbers, or any information that could be used to identify the participating human trafficking survivors (Merriam, 2009). After they have signed the informed consent forms, the researcher will meet with each of them, individually, to fully explain the purpose of the study, who will see the results, the types of questions, confidentiality rules, their right to refuse to answer any question, and their right to end the interview at any time. Any other privacy issues the interviewees have will be thoroughly addressed, as anonymity is of utmost importance due to the highly sensitive nature of human trafficking.

\section{Data Collection Tools}

This research study will incorporate a qualitative design, with interviews being used as the primary method of gathering data. The semi-structured, face-to-face interviews will be held with each of the participants individually. One of the advantages to this type of interview is that participant's answers can be explored further (Fink, 2012). The interview questions will address the survivor's human trafficking experience and subsequent involvement with the Victim Advocacy Program, any institutional betrayal encountered, whether or not the program is beneficial, how the program has helped or hindered them, and what areas could be improved upon. The interview questions for the advocates will address their perception of advocate responsibilities, the strengths and weaknesses of the after care services provided, ideas for 
improvement and opportunities for growth, as well as the prevention of institutional betrayal within the program.

Each participant will have already received an informed consent letter, and the researcher will go over this information again before beginning the interview. Participants will also be reminded that participation is voluntary and anonymous, and that they can withdraw at any time. Each interview will last approximately 60 minutes, will be audio recorded (if permission is granted), the answers will be transcribed, and any identifying information will be changed (Krueger \& Casey, 2009). All collected information will remain confidential in order to maintain privacy (Creswell, 2012; Merriam, 2009). The interview questions, informed consent form, and interview transcripts will be included in appendices.

\section{Data Analysis}

After conducting the interviews, there will be a more thorough understanding of human trafficking and the importance of after care, as well as whether or not institutional betrayal applies to human trafficking survivors, and how. Qualitative data derived from the interviews with human trafficking survivors and advocates will be analyzed in order to answer Research Question One and Two. The interview transcripts will be coded for consistencies and analyzed for emerging themes (Krueger \& Casey, 2009; Merriam, 2009) in terms of trauma, betrayal, and after care. The aftermath survivors experience will be examined through the lens of institutional betrayal, specifically focusing on the after care services provided by law enforcement officials (when applicable) and the Victim Advocacy Program. The researcher will review the interview transcripts in order to ensure an understanding of interview data, as well as to ensure internal consistency (Krueger \& Casey 2009; Merriam, 2009). The strengths of the Advocacy Program will be discussed, as well as the specific areas where improvement is needed. The implications of 
institutional betrayal (if any) on survivor's traumatic experiences will also be included, and how to improve current practices. Together, this information will increase understanding of human trafficking, the impact of the secondary trauma of betrayal on survivors, and why functional and effective after care services are crucial.

\section{Limitations, Assumptions, and Design Controls}

Generalizability and transferability of data will be one of the limitations of this study. Only human trafficking survivors in one Advocacy Program, in one state, are involved. The research findings of this study will not be an accurate representation of other programs in other areas as this study is specifically evaluating the Victim Advocacy Program of the Missouri Sheriffs' Association, thereby limiting transferability (Creswell, 2012). Researcher bias may also be considered a limitation, as the researcher received Victim Advocacy training through the Missouri Sheriffs' Association Training Academy in April, 2014 and is a Volunteer Advocate in another location, approximately three hours away. However, the researcher does not have a direct association with any of the survivors in the program, including those participating in the study, nor is the researcher involved in the day-to-day operations of the advocacy program or the Missouri Sheriffs' Association in any way. Nevertheless, the researcher recognizes a connection with this program and is aware of potential biases.

One of the previously held assumptions before starting this study is that institutional betrayal does apply to human trafficking survivors. Given the number of different organizations

and people a survivor comes in contact with, it is assumed that institutional betrayal is occurring at some level. A second assumption is that the Victim Advocacy Program is meeting human trafficking survivor's needs. Although it us unknown how helpful the program actually is, it is assumed to be helpful. It is also assumed there are weak areas that need to be improved upon, 
and/or new developments that need to be implemented in order for the program to more effectively help survivors.

\section{Definition of Key Terms}

After Care Services: Can include a variety of support services provided to human trafficking survivors, such as medical care, transportation, shelter, and victim protection (Logan, Walker, \& Hunt, 2009; Okech, Morreau, \& Benson, 2011).

Coercion: Can involve threats of serious harm or physical restraint against any person; any scheme, plan or pattern intended to cause a person to believe that failure to perform an act would result in serious harm to or physical restraint; or the abuse or threatened abuse of the legal process (Hodge, 2014; Kim, 2007; Shigekane, 2007).

Cognitive Adaptations: Occurs when victims have been psychologically manipulated and are unable to see the reality of the situation, or develop an alternate reality that is not accurate; mental changes occur and cognitions may become narrowed, distracted, or numbed due to the victims focusing all their energy on survival and threat vigilance (Clawson, Dutch, \& Williamson, 2008; Gross, 1998a; Gross, 1998a\&b).

Force: Can involve the use of physical restraint or serious physical harm. Physical violence, including rape, beatings, and physical confinement, is often employed as a means to control victims, especially during the early stages of victimization, when the trafficker breaks down the victim's resistance (Hodge, 2014; Hodge \& Leitz, 2007; Hom \& Woods, 2013; Zimmerman, Hossain, \& Watts, 2011).

Fraud: Involves false promises regarding employment, wages, working conditions, or other matters. Individuals might travel to work at a farm or factory only to find themselves 
manipulated into forced labor; others might reply to advertisements for service industry jobs, but be forced into prostitution once they arrive (Hodge, 2014; Logan, Walker, \& Hunt, 2009).

Human Trafficking: The recruitment, harboring, transporting, supplying, or obtaining a person for labor or services through the use of force, fraud, or coercion for the purpose of involuntary servitude or slavery (Logan, Walker, \& Hunt, 2009).

Institutional Betrayal: Occurs when an institution causes harm to an individual who trusts or depends on that institution; possible for a person to feel just as betrayed by an institution as they can by another person. Betrayal may be actively committed or occur via omission of protective, preventative, or responsive actions. This secondary trauma worsens the existing trauma (Logan, Walker, \& Hunt, 2009; Parnitzke, Smith, \& Freyd, 2013; Parnitzke, Smith, \& Freyd, 2014).

Mental Defeat: The perceived loss of all autonomy, a state of giving up in one's mind all efforts to retain one's identity as a human being with a will of one's own Ehlers, Maercker, \& Boos, 2000).

Misreporting: To give a false or inaccurate account of something (Smith, Gomez, \& Freyd, 2014 ) .

Psychological Entrapment: Occurs due to psychological techniques used to increase victims' sense of isolation and dependence on traffickers: traffickers take victim's identification, restrict communication, threaten their loved ones, confine them, and keep them isolated; the powerful effect of psychological entrapment ensures compliance from victims (Kim, 2007; Logan, Walker, \& Hunt, 2009). 
Post-Traumatic Stress Disorder (PTSD): A condition of persistent mental and emotional stress occurring as a result of injury or severe psychological shock, typically involving disturbance of sleep and constant vivid recall of the experience, with dulled responses to others and to the outside world (Hodge, 2014; Smith, Gomez, \& Freyd, 2014).

Rationalizing Process: An attempt to explain or justify (one's own or another's behavior or attitude) with logical, plausible reasons, even if these are not true or appropriate (Gross, 1998a, p. 284).

Sex Trafficking: Occurring when a commercial sex act is induced by force, fraud, or coercion, or in which the person induced to perform sex acts is under 18 years of age, in which case it is not necessary to prove any of the three (Logan, Walker, \& Hunt, 2009, p. 4).

Survivor: Refers to those (former victims) who have been liberated and denotes life after trafficking (Smith \& Freyd, 2014; Smith, Gomez, \& Freyd, 2014).

Trafficking Victims Protection Act (TVPA): This act provides the tools to combat trafficking in persons both worldwide and domestically. The Acts authorized the establishment of G/TIP and the President's Interagency Task Force to Monitor and Combat Trafficking in Persons to assist in the coordination of anti-trafficking efforts (Logan, Walker, \& Hunt, 2009, p. 4).

Victim: Anyone who has been trafficked has been a victim, and the ones trapped in a trafficking situation remain victims (until liberated) (Smith \& Freyd, 2014; Smith, Gomez, \& Freyd, 2014). 


\section{Significance}

\section{Scholarship}

The findings of this study provide some interesting insights into the reality of human trafficking and what is meant by effective after care services. One contribution will be a better understanding of human trafficking and the specific types of trauma associated with it. This is not a subject everyone is familiar with and there is still much literature to be added. Moreover, this study will make an important contribution by examining human trafficking specifically through the lens of institutional betrayal, a topic on which little research exists. After care service providers can betray victims and worsen survivors existing traumatic experience, which is important to understand and thereby improve upon. Additionally, this study contributes to the rather small body of literature on after care programs available for human trafficking survivors, including the importance of program effectiveness.

\section{Practice}

The implications regarding human trafficking survivor's experiences and after care services will be straightforward. The importance of programs that specifically address the various needs of human trafficking survivors will be demonstrated by the individual experience of each survivor; there are specific emotional and mental traumas that survivors face in the aftermath of trafficking. These traumas are only exacerbated if the survivors have experienced institutional betrayal. Depending on their situation, some survivors may have never had what is considered a "normal" life and have nowhere to go, or do not want to return to a dysfunctional home. Others may have a home and support system, but still need help re-acclimating to society. After care services are often the only resource survivors have access to and it is imperative that 
their specific needs are met accordingly, whether through a long term care facility or outpatient services.

Another contribution of this study is the insight into what makes after care services effective, based on the opinion of survivors themselves. Law enforcement officials, crime unit managers, organization directors, and others responsible for helping survivors and /or designing and putting after care programs in place can get a better idea of what would actually be helpful, rather than what they think would be helpful. Ensuring effective after care services is of utmost importance, as institutional betrayal worsens the long list of traumatic effects of human trafficking survivors.

\section{Summary}

Human trafficking is an escalating problem affecting every country in the world, including the United States. The awareness campaigns and prevention efforts put forth by a variety of both organizations and individuals is impressive and is not to be discounted. However,

prevention is not enough. Having effective after care services in place will help ensure survivors are able to have their specific needs met when they have escaped or been liberated from this unimaginable horror. Examining human trafficking through the institutional betrayal lens further exemplifies the impact of trauma and how it can be exacerbated in a number of ways by those who victims are dependent on for help and after care. This helps demonstrate why effective survivor programs are so important. 
SECTION TWO

PRACTITIONER SETTING FOR THE STUDY 


\section{Introduction}

The Missouri Sheriff's Association (MSA) actively worked to close a gap in the services to crime victims by launching the Crime Victims Unit (CVU). The Victim Advocacy Program of the CVU strives to enhance the availability of immediate, comprehensive assistance to crime victims in all Missouri counties without prosecutor-based victim advocates, as well as in the counties that have prosecutor-based victim advocates but are underserved. This Victim Advocacy Program fills a void for victims by offering necessary advocacy services such as crisis intervention, transportation, support, and information about the criminal justice system. Through the MSA CVU, Victim Advocates are doing what they can to ensure human trafficking survivors are receiving the assistance they need.

\section{History of the Organization}

The Missouri Sheriffs' Association (MSA) was founded in 1945 and is located in Jefferson City, the capital of the state of Missouri. There are approximately 43,000 residents of Jeff City, making it the $15^{\text {th }}$ largest city in the state ("City of Jefferson", 2014). The MSA is a non-profit organization with a mission to support the state Sheriffs Offices and the Constitution through legislative efforts, training, and technical assistance ("Missouri Sheriffs' Association", 2015). It is home to the Missouri Sheriffs' Association Training Academy (MSATA) and offers basic peace officer training; MSATA has trained over 31,000 Missouri peace officers in the past four years and ranked number one in the state for total number of basic academy graduates per

year for the fourth year in a row ("MSA", 2015). MSATA also offers grant funded trainings and continuing education trainings such as Interview and Interrogation, Firearms Instructor Course, 40 Hour Basic Jail Officer Training, and Management Development courses ("MSA", 2015). Academy instructors are working or retired deputies, police officers, highway patrol 
troopers, federal law enforcement officers, juvenile officers, judges, firefighters, attorneys, and other professionals local to the communities ("MSA", 2015). All instructors are licensed and regulated by the Peace Officers Standards and Training (POST) Program, a Division of the Missouri Department of Public Safety ("MSA", 2015). The MSATA offers both full-time and part-time classes, at the Jefferson City location as well as other cities within the state including: Camdenton, Chillicothe, Clinton, Kirksville, Mr. Vernon, Reeds Spring, Salem, Platte County, Union, Waynesville, West Plains, and Poplar Bluff (“MSA”, 2015).

The Missouri Sheriffs' Association releases multiple publications for use in their offices and others across the state. The Missouri Sheriff magazine is available online on the MSA website and on sheriffs' county web sites across the state ("MSA", 2015). The Annual Missouri Sheriff's Directory is distributed to Missouri sheriffs, deputies, jail administrators, and other law enforcement personnel and lists the name, address, phone, and fax numbers of every sheriff in the state, plus police departments, correctional facilities, and more ("MSA", 2015). This directory is relied on heavily by sheriffs and their staff; it is published annually in March and is available for purchase in both printed and electronic format. The MSA also hosts five conferences a year, distributing a full color program showcasing the agenda, presenters, vendors, and future conferences (“MSA", 2015).

The Missouri Sheriffs' Association has 10 full-time staff members and four adjunct staff members. These 14 employees make up the Crime Victims Unit, the Training Academy, and also include office, grounds, and maintenance staff. There is also an eight member Board of Directors, made up entirely of Sheriffs from different counties across the state. As it is a nonprofit organization, the MSA exists through the efforts of Missouri sheriffs and the financial support from honorary members. An honorary membership is $\$ 25.00$ and a business membership 
is $\$ 50.00$; this membership supports stronger legislative support, stronger and safer communities, the future of Missouri law enforcement, and support for Missouri's sheriffs and their staffs ("MSA", 2015). The MSA 2013 tax return indicated total revenue of $\$ 1,816.996$ and total expenses of $\$ 1,798,021$; total program expenses totaled $\$ 1,511,748$ (83\% of total revenue) and total administrative expenses totaled $\$ 286,273$ (17\% of total revenue) (“MSA", 2015).

\section{Crime Victims Unit and Victim Advocacy Program}

The Crime Victims Unit (CVU) was started in 2011 in order to provide crisis intervention, support, assistance, and information to Sheriff's Offices and much needed help to crime victims in all areas of Missouri (MSA CVU Program Services, Policies, \& Procedures, 2013). The Victim Advocacy Program is part of the CVU and includes the Executive Director, a Grants Coordinator/Program Manager, a Victim Advocate Case Manager, and a Human Trafficking Specialist; both the Case Manager and Trafficking Specialist are Victim Advocates, and there are also 11 Volunteer Victim Advocates in Jefferson City. The telephone line is in operation 24 hours a day, seven days a week, with all calls returned within one hour. Appointments may be arranged by the Victim Advocate Case Manager or other Advocates on a case-by-case basis seven days a week (MSA CVU Program Services, Policies, \& Procedures, 2013).

The primary goal of the Advocacy Program is to enhance the availability of immediate, comprehensive services to crime victims through law enforcement communities in Missouri (MSA CVU Program Services, Policies, \& Procedures, 2013). Supporting crime victims not only helps balance the scales of justice by acknowledging the losses suffered due to victimization, but also offers the victim and their family a place in the process. Advocates in the Victim Advocacy Program are called upon to provide emotional support and assistance to the victim(s) of a crime, 
as well as assistance with any problems victims or witnesses may experience because of the crime ("MSA", 2015). The Advocates can also provide verification of the crime to the appropriate organizations and/or persons. The Victim Advocacy Program provides a multitude of victim services including: Crisis Intervention, Referrals, Assistance with Crime Victims Compensation, Transportation, Shelter, Assistance during Interviews, and Accompaniment to Court ("MSA", 2015). Some of the other services provided by Victim Advocates include but are not limited to: information on victimization and victims' rights; safety planning; support groups; counseling and therapy; education; intervention and advocacy with creditors, landlords, and employers; intervention with medical and mental health providers; referrals to mental health services, substance abuse services, social services, and legal services; and assistance with document replacement (“MSA”, 2015).

The Crime Victims Unit, and all of the Victim Advocates, follow the standards set forth in the Missouri Crime Victim Services Unit (MoCVSU) Standards and Code of Ethics ("MSA", 2015). All victims are treated respectfully and utmost confidentiality is guaranteed. As part of the intake process, victims are informed of their individual rights and are given access to the CVU's policies for working with each county; the Victim Advocates are required to review the terms of Confidentiality and the victim is asked to sign the document ("MSA", 2015). However, confidentiality will be waived if a client is: homicidal, suicidal, under 18 and being sexually or physically abused, abusing drugs, and/or abusing a child (MSA CVU Program Services, Policies, \& Procedures, 2013). In these cases, the Executive Director or one of the Managers will talk to the client and ascertain the need to contact the proper authorities, which can include but are not limited to: Police; Division of Family Services; Child Abuse hotline, Drug Abuse hotline, and suicide hotline; and the MO Coalition of Domestic \& Sexual Violence (p.22). 


\section{Organizational Analysis}

Although the Missouri Sheriffs' Association (MSA) has a basic structural frame, with an Executive Director at the top of the hierarchy design (Bolman \& Deal, 2008), aspects of a human resource frame are more apparent in this organization. For instance, the MSA emphasizes support and empowerment of employees, as evidenced by the organization's use of distributed leadership; there are two managers within the Crime Victims Unit (CVU) alone - a Division Manager and a Program Manager. Moreover, the CVU Division Manager is also the Victim Advocate Case Manager; although she reports to the CVU Program Manager, she has the freedom to make decisions concerning the Advocacy Program as she is the one directly overseeing it, and she is also responsible for leading staff and Victim Advocates. "Our work environment is unique and progressive because some of our Advocates work remotely across the state" (K. Case, personal communication, June 3, 2016). It is understood that no one knows the Advocacy Program, or the Advocates, as well as she does; thus the program is left in her capable hands. This organization focuses on people and how to let them do their jobs in the best way possible; this helps ensure high employee morale, which is vital in this line of work.

The human resource frame centers on what organizations and people do to and for one another (Bolman \& Deal, 2008). Human resource practices help empower employees; empowerment is informing employees, encouraging participation, redesigning work, infusing work with meaning, fostering teams, and promoting egalitarianism (p. 149). Furthermore, openbook management is built around the notion of informing employees about where they work. It sends a signal that management trusts people, creates an incentive for employees to contribute, and provides information to help do a better job (p. 150). The leaders at the Missouri Sheriffs' Association - the Executive Director, CVU Program Manager, and the Victim Advocate Case 
Manager - ensure everyone is informed about important information that is likely to impact the organization and explain the reasoning for changes and decisions. This helps employees feel connected to the work environment, which is especially important for the Advocates that do not live in Jefferson City.

Participation allows workers to influence decisions about work and helps increase morale and productivity (Bolman \& Deal, 2008). By meeting with employees, in person and via skype when necessary, to discuss different views on situation, each of the leaders help indicate everyone's input is important. This increases morale as everyone is aware their voices matter. Moreover, egalitarianism goes beyond participation and implies that employees participate in decision making (p. 155). This is indicative of the organization as all employees have an active voice in the decision-making process. While the MSA Executive Director is ultimately responsible for making final decisions, the Program Manager and Victim Advocate Case Manager have input, and all employee opinions are heard and taken into account as well.

The leadership style one prefers can influence the frame used for organizational analysis; likewise, frame preference influences leadership effectiveness (Bolman \& Deal, 2008). The human resource frame is imperative because administrators who are authoritarian, insensitive, do not care, or do not communicate effectively cannot be effective leaders (p. 331). Especially in an organization such as the MSA, people are vital; the shared goal of everyone who works there cannot be realized without effective leadership.

\section{Leadership Analysis}

Scholars have developed countless definitions of leadership, with different themes constantly emerging. Northouse (2013) identified leadership as a process where an individual influences a group in order to achieve a common goal, and that is the definition relied upon for 
the purpose of this study. Moreover, the situational approach ascertains that different situations call for different types of leadership (p. 99). Although trait approach holds that leaders are born with "great" qualities while others are not (p. 19), it fails to consider the importance of context. Fortunately, the leaders at the MSA do consider the importance context, and this makes all the difference. Effective leadership is not just about the leader, but also how they handle situations and whether or not they achieve goals.

The CVU Program Manager and Victim Advocate Case Manager both report to the Executive Director of the MSA ("MSA", 2015). The Human Trafficking Specialist and other Victim Advocates report to the Victim Advocate Case Manager, who reports to the Grants Coordinator/CVU Program Manager. The MSA also employs a Program Coordinator, who helps ensure compliance with state standards and MoCVSU guidelines, and interacts between the leaders. ("MSA", 2015). This distributed leadership helps ensure responsibilities are delegated effectively and that the Case Manager has the autonomy to function as a leader in her own right within the Victim Advocacy Program. Everyone has the same shared goal of helping others and they work together to achieve it.

The Situational Leadership Model developed by Hersey and Blanchard (Bolman \& Deal, 2008) focuses on two dimensions of leadership, task and people, which indicate four leadership styles: supporting, delegating, coaching, and directing. The Victim Advocate Case Manager relies on situational leadership, in her day-to-day work with the CVU and Advocacy Program. "I am a different type of leader depending on the particular situation, the type of victim, or the person I am working with. My role as an Advocate also requires being one kind of leader when working with survivors and another when working with law enforcement and agencies" (K. Case, personal communication, June 3, 2016). As the Case Manager, delegation and directing 
when necessary are obvious parts of the job, but coaching is her preferred style when working with her team on a new project or tackling a new task they are not familiar with. And while she relies on her supportive style of leadership most often when working directly with victims and survivors, her coaching style also comes into play. "When survivors are progressing and you're working to help them get to that next point, whether it be living on their own or starting a job, more than support is required. This is all brand new for them and you have to coach them through it sometimes, help them see they can do this and that they can succeed in life" (K. Case, personal communication, June 3, 2016). This ability to effectively measure situations and correctly determine which type of leadership style is necessary is a strength of the Victim Advocate Case Manager that positively impacts everyone she works with, from law enforcement officers to human trafficking survivors.

\section{Implications for Research in the Practitioner Setting}

Victim Advocates provide each victim they encounter with much needed emotional support and practical assistance in order to help them make the best decisions for themselves, their family, and the case moving forward (MSA CVU Program Services, Policies, and Procedures, 2013). Advocates actively network with other service agencies and organizations in the community, and similar types of groups throughout the country, in order to offer the best possible care to their clients. This dedication is important, as it has been proven that how law enforcement deal with crime victims in their time of trauma ultimately affects the way they handle the process of the criminal justice system. In fact, just by simply participating in the system, the victim can be re-traumatized and re-offended (p. 6). Although the responsibilities are vast, crime victims in trauma have special needs and Victim Advocates of the MSA CVU are working to meet these needs in a variety of ways. Victim Services are specifically focused on six 
key areas: 1) crisis intervention, 2) referrals, 3) assistance with crime victim compensation, 4) transportation/shelter, 5) assistance during the interview phase, and 6) accompaniment to court ("MSA", 2015). Advocates also offer additional services and referrals as needed.

\section{Crisis Intervention}

According to the universal principles of crisis intervention, Jackson-Cherry and Erford state "Intervening as quickly as possible is imperative. Resource mobilization should be immediately enacted in order to provide victims with the tools they need to return to some sort of order and normalcy, in addition to enable eventual independent functioning" ("Missouri Sheriffs' Association", 2015). Victim Advocates, as well as all volunteers, with the Victim Advocacy Program are trained in crisis intervention and follow these universal principles as described by Jackson-Cherry and Erford ("MSA", 2015). Advocates also address crisis intervention by expressing an understanding that becoming a victim is a moment of crisis where their - the victim's - usual coping abilities are inadequate to meet the demands of the current situation. Victimization occurs as the victim tries to deal with the stress from coping with the effects of the crime ("MSA", 2015).

\section{Referrals}

Victim Advocates provide information about the criminal justice process, available resources, and referrals by providing “victim packets". These packets include victims' rights materials, resource information, and victims' compensation applications for all agencies available to crime victims ("MSA", 2015). Also included in the victim packets are confidentiality policies and procedures, subsequent steps of case processing and handling, the case number and contact person, contacts for future crisis or emergency, what to do if threatened or intimidated, and information on safety planning ("MSA", 2015). It is also important that 
Advocates help the client work through emotions and help them realize that the victimization does not define them or take over their life (MSA CVU Program Services, Policies, and Procedures, 2013).

\section{Assistance with Crime Victims Compensation}

The Crime Victims' Compensation Program financially assists people who have sustained physical or psychological injury as a result of a violent crime by paying for reasonable medical and counseling expenses, as well as lost wages if the victim was employed ("MSA", 2015). To receive assistance, victims must fill out an application and provide eligibility information. Victim Advocates assist in this process by working with the victim to gather all the necessary data, including police report numbers and receipts ("MSA", 2015). However, in order to be eligible, the victim must meet certain requirements including: 1) the application must be filed within two years of the crime date, or in cases involving persons under 18, within two years of discovery, 2) the victim must cooperate with law enforcement and prosecution if an alleged offender is identified, and 3) the victim must report the crime to law enforcement within 48 hours of the crime unless good cause is shown, or in cases involving person under 18, within 48 hours of discovery. (A victim residing in a certified shelter for up to five days from the crime date may constitute good cause for delay in reporting the crime) ("MSA", 2015). These are just some of the requirements and additional documents may be requested throughout the course of the investigation.

\section{Transportation/Shelter}

Some of the victims may not have anywhere safe to go, or any means to get there. When transportation or shelter is needed, Victim Advocates arrange assistance through local resources, allied agencies, cab and bus companies, local law enforcement, and hotels ("MSA", 2015). 
Whether it is transportation one time to an immediate safe location, or if both transportation and shelter are needed continually in the days and weeks following victimization, Advocates ensure their clients have a safe place to stay and reliable transportation when necessary.

\section{Assistance During the Interview Phase}

Help throughout this phase involves participating with the law enforcement agency on behalf of the victim. Advocates understand that crime results in injuries and losses felt by the victim and, more importantly, they understand that the reactions experienced and expressed by the victim are not always in proportion to the loss experienced ("MSA", 2015). For instance, one victim's reaction immediately following a crime may not seem extreme, while for another victim, even a perceived threat can cause an extreme crisis reaction. While it may be possible for some victims to work directly with law enforcement immediately, most need more time. The Victim Advocate will therefore act as a liaison between law enforcement and the victim to assure the victim's recovery while also assisting in the investigation process ("MSA", 2015).

\section{Accompaniment to Court and Follow-Up}

An Advocates job is not done after an investigation is over, or even after charges are filed. Once the investigation is complete, Victim Advocates maintain contact with victims while the case is being reviewed by the prosecutor and, if charges are filed, relationships will be forged with court advocates (if available). If charges are not filed, an Advocate will make all attempts necessary to assure the victim is connected with family support if possible, as well as community resources. Advocates work to ensure that every victim receives services they have a right to under Missouri law, including medical visits and counseling ("MSA", 2015). Advocates also make a follow-up plan for each victim, continuing to help and make referrals as needed in the 
future, as long as the victim gives the Advocate permission to remain in contact (MSA CVU Program Services, Policies, and Procedures, 2013).

Although many benefits can be identified with the Victim Advocacy Program, there will always be room for improvement. Therefore, the MSA encourages clients to express any dissatisfaction with the services of the Advocacy Program through a phone call, letter, or inperson visit; all complaints are brought to the attention of the Executive Director and Managers (MSA CVU Program Services, Policies, \& Procedures, 2013). This indicates the Victim Advocacy Program not only cares about helping victims, but also has a strong desire to improve practices by seeking out the opinions of those who have been involved with the program. Records are kept and the qualitative data collected in this study will help supplement the data the program is already collecting on its own. Specifically, the effectiveness of services offered by the Victim Advocacy Program and whether or not victims have experienced institutional betrayal are implications for research. How current services can be improved, what new services can be added, the type of trauma associated with institutional betrayal, and steps to eliminate it in the future (if it is happening) are all important questions.

\section{Summary}

The MSA acknowledged the importance of victim assistance when they launched the Crime Victims Unit (CVU). The Victim Advocacy Program of the CVU takes that initiative even further and actively strives to enhance the availability of immediate, comprehensive assistance to crime victims in all Missouri counties that do not have prosecutor-based victim advocates, as well as in the counties that offer prosecutor-based victim advocates but are understaffed. Victim Services specifically focus on the six key areas of crisis intervention, referrals, assistance with compensation, transportation/shelter, assistance during the interview phase, and accompaniment 
to court ("MSA", 2015). Victim Advocates are also responsible for assisting Missouri law enforcement by: 1) providing a response to the emotional and physical needs of crime victims, 2) assisting primary and secondary victims and help stabilize their lives after victimization, 3) helping victims understand and participate in the criminal justice process, and 4) providing victims with a measure of safety (MSA CVU Program Services, Policies, \& Procedures, 2013). By focusing on key areas of importance and following a thorough procedure, Victim Advocates are continually working to improve the practices in place within the Victim Advocacy Program. Through the MSA CVU, Victim Advocates are doing what they can to ensure human trafficking survivors are receiving the assistance they need. 
SECTION THREE

SCHOLARLY REVIEW FOR THE STUDY 


\section{Introduction}

While there is an agreement something must be done about human trafficking, trying to figure out what that something is has proven to be a challenge. There is a lot of talk about the importance of prevention campaigns; similarly, much emphasis is placed on increasing awareness. Although both of these concepts are important, neither are enough. Modern day slavery is happening; some of it is being prevented, but certainly not all. There needs to be an effective plan in place that addresses what to do when it does happen, not just how to help prevent it.

Human trafficking is increasingly happening across the United States, including in Missouri and the neighboring states (Williamson and Prior, 2009). Although recruitment of victims and selling sexual services can easily take place anywhere, smaller cities in the Midwest have been identified as high recruitment areas where traffickers manipulate and force youth into trafficking, and move them around to other cities throughout the country (p. 48). Prevention and awareness campaigns are not going to help once someone has fallen victim to trafficking. Survivors are in need of effective after care services in order to help overcome past trauma and successfully rebuild their lives.

Preventative measures and increased awareness is not enough to tackle this escalating crisis, nor is it helpful to survivors of human trafficking who need help after it has already happened. Focusing on human trafficking specifically through the lens of institutional betrayal illustrates the emotional and mental aftermath that survivors experience and how betrayal by trusted institutions may exacerbate these traumatic effects, further demonstrating why effective after care programs are necessary. Past literature helps shed light on human trafficking, as well as why more research in the area of after care services and survivor rehabilitation is necessary. 


\section{Human Trafficking}

Human trafficking is not a term that is easily defined as there are many different types, ranging from indentured servitude to forced labor to sex trafficking. Human trafficking is defined by the Trafficking Victims Protection Act (TVPA) of 2000 as "the recruitment, harboring, transporting, supplying, or obtaining a person for labor or services through the use of force, fraud, or coercion for the purpose of involuntary servitude or slavery" (Logan, Walker, \& Hunt, 2009, p. 4). Additionally, sex trafficking is defined as occurring when a commercial sex act is induced by force, fraud, or coercion, or in which the person induced to perform sex acts is under 18 years of age, in which case it is not necessary to prove any of the three (p.4). The use of coercion can be direct and physically violent, as most imagine it, or it can be through psychological means, which is more often the case. Moreover, people who have been trafficked have not given consent and even if there was initial consent, it has been rendered meaningless by the coercive, deceptive, or abusive means used by the trafficker (Shigekane, 2007). These working definitions successfully put human trafficking into terms that can be understood, but they do not fully convey what this violation of basic human rights entails.

The key elements of the TVPA indicate it is illegal to exploit a person for profit or personal services (Logan, Walker, \& Hunt, 2009), but it is happening across the United States, including in Missouri and neighboring states. For instance, several brothels disguised as spas where women served as sex slaves were uncovered in Rockford, Illinois (Hounmenou, 2012). People are also trafficked for labor, with victims held in domestic servitude as unpaid nannies and maids in wealthy Illinois suburbs. Additionally, Chicago is considered a major crossroads of human trafficking. Likely due to its mid-country location and transportation infrastructure, the O'Hare International Airport has become a strategic transit location for traffickers to transport 
victims and distribute them to other states. St. Louis, Missouri is also a hub of human trafficking and the U.S. Department of Justice ranked it one of the top 20 jurisdictions in the country (Nichols \& Heil, 2014). This city is susceptible to trafficking due to a number of risk factors; it, too has an international airport, plus it is at the center of cross country interstates, making transportation and the disappearance of victims less complicated ("The Covering House", 2013). St. Louis has also been identified as the top city in the nation for strip clubs per capita, which have been found to be underground venues for trafficking (Nichols \& Heil, 2014). But how does human trafficking occur? Who are the victims? Many incorrectly envision victims bound and chained in dark basements when in reality, traffickers prefer psychological bondage. And anyone can be a victim.

\section{Traffickers and the Victims}

Traffickers rely on a variety of methods to recruit victims. Deceptive promises such as employment, modeling opportunities, study abroad programs, involvement in entertainment industries, and other attractive offers are used to lure people in; they discover too late they have been duped (Hodge, 2014). Victims believe they are taking legitimate jobs such as childcare, modeling, landscaping, or domestic work; some sign bogus contracts, making it appear legitimate and psychologically binding them even more to the trafficker (Logan, Walker, \& Hunt, 2009). "A predator does not care who you are or where you come from. They find a vulnerability in a person and they play on that" stated Denise, a human trafficking survivor ("The Covering House", 2013). For example, Holly was approached by Greg, an attractive guy in his 20 's, at the mall and they exchanged phone numbers. While developing their relationship over the course of a few months, he picked up on her love of music and subsequently began feeding her dreams of being in the music industry; he told her he knew famous musicians and that his 
contacts could get her career going. After convincing her to run away with him, Greg took Holly to Atlantic City. He dropped her off at a hotel with one of his "girls" and she quickly caught on that Greg had many girls, and that she was now one of them. He began selling her body to random men on the street within hours, and raped her in order to "test out his goods" (Smith, p. 106). She was fourteen years old. Traffickers are willing to spend a great deal of time recruiting victims, as Greg did with Holly. This is because it is easier for traffickers to manipulate and control victims if they have a relationship (Hodge, 2014). Traffickers may also involve victims in illegal activities, such as selling drugs and theft, so they are less likely to seek out law enforcement. After a trafficker has successfully entrapped a victim, the next phase begins.

Like Holly, most individuals do not realize they are victims of trafficking until they are being exploited in the sex industry or other forms of coerced labor (Hodge, 2014, p.113). Once traffickers have a victim in this situation, they employ various mechanisms to control them and ensure they do not leave or contact law enforcement. A review of prosecuted cases in the U.S. indicated the frequent use of beatings, rape, and murder (Roby, Turley, \& Cloward, 2008). In addition to physical brutality, psychological techniques are used to increase victims' sense of isolation and dependence on traffickers (Hodge \& Leitz, 2007). For instance, traffickers take victim's identification, restrict communication, threaten their loved ones, confine them, and keep them isolated (Zimmerman, Hossain, \& Watts, 2011). Victims are often forced to engage in humiliating sex acts or use drugs and then threatened with exposure of these activities to the police, family members, or children (Hom \& Woods, 2013). The goal is to break victims psychologically so they become subservient to the desire of traffickers (Hodge, 2014). It is much more efficient to subordinate people psychologically rather than keep them constantly chained up (Logan, Walker, \& Hunt, 2009). 
The powerful effect of psychological entrapment gives traffickers ultimate compliance even if given a chance to escape, the victim is unlikely to take the risk (Logan, Walker, \& Hunt, 2009). Four main themes about what keeps people entrapped have emerged from research: fear, lack of knowledge about alternatives, isolation, and physical and psychological confinement. Fear of physical and sexual violence is not unfounded given that violence is implicit and explicit. Threats to family members are another common fear; a very real one given what traffickers are capable of. Victims also may not be aware of services to help them or believe there are no options other than to stay in the situation. Thirdly, isolation from the public is accomplished by limiting contact with friends, family, and outsiders, and by monitoring communication to ensure it is superficial (p. 13). This simultaneously reduces resistance and increases dependence on the trafficker. Finally, although physical confinement is sometimes a factor, psychological confinement is the most powerful tool (Kim, 2007). Traffickers also rely on the forced use of alcohol and drugs to turn victims into addicts and employ acts of degradation and abuse at any time, for any reason. One victim stated, "They just broke me down, shattered my will and hopes. I was humiliated" (Raymond, D'Cunha, Dzuhayatin, Hynes, Rodriguez, \& Santos, 2002, p. 196).

\section{Effects and Cognitive Adaptations}

The powerful effects of psychological coercion play a key role in entrapment and continued enslavement (Hodge, 2014). Traffickers can manipulate and psychologically control victims so effectively that some do not see the reality of the situation, or develop an alternate reality that is not accurate. These adaptations to slavery are not uncommon. The goal is to break victims completely and ensure submission, by any means necessary. Once victims have submitted, mental changes occur and cognitions may become narrowed, distracted, 
or numbed due to the victims focusing all their energy on survival and threat vigilance (Clawson, Dutch, \& Williamson, 2008; Gross, 1998a\&b). Victims may also accommodate threatening or aversive environments by fantasizing, shifting attention away from the threat, or reappraising the situation into one that is more easily accepted - a rationalizing process which "transforms a situation so as to alter its emotional impact" (Gross, 1998a, p. 284). This can lead to several issues, such as a victim reappraising an aversive situation as not as bad as it could be, minimizing harm, justifying the situation, comparing it to others who are worse off, or accepting the situation. Mental defeat may also be a response to the circumstances of trafficking. Mental defeat is defined as "the perceived loss of all autonomy, a state of giving up in one's mind all efforts to retain one's identity as a human being with a will of one's own" (Ehlers, Maercker, \& Boos, 2000, p. 45). It is associated with total subordination, feeling as an object to others, loss of self-identity, willingness to do whatever is asked, and not caring if one lives or dies. The feelings of mental defeat are also associated with more chronic posttraumatic stress disorder (PTSD) and depression (p. 46).

In short, the stress of the trafficking situation is almost guaranteed to create dissonance between the victim's thoughts, feelings, and behavior, which in turn negatively impact healthy coping mechanisms and rational decision making (Logan, Walker, \& Hunt, 2009). This has significant consequences on the victim's health, mental health, and recovery (p. 17). Elevated levels of depression, anxiety, PTSD, substance use and abuse, hostility, self-harm, suicidal ideation, and suicide are just some of the traumatic effects (Hodge, 2014). Others include guilt, memory loss, dissociation, insomnia, shame, mistrust of others, social withdrawal, loneliness, loss of self-esteem, a sense of apathy or resignation, extreme forms of submissiveness to authority, and loss of personal initiative and autonomy (p. 115). The devastating impact 
trafficking has on victims demonstrates why effective after care is imperative. However, victims are often betrayed by those trusted to help, worsening an already traumatic experience. Research results have shown that institutions have the power to cause additional harm to assault survivors (Smith \& Freyd, 2013). Examining human trafficking through a specific theoretical lens will help illustrate the impact of institutional betrayal.

\section{Institutional Betrayal}

Institutional betrayal occurs when an institution causes harm to an individual who trusts or depends on that institution (Parnitzke, Smith, \& Freyd, 2014). It is possible for a person to feel just as betrayed by an institution as they can by another person; this is because institutions, such as the military and universities, often obtain the same high level of trust and dependency from their members that is common in relationships between people (Parnitzke, Smith, \& Freyd, 2013). This relationship to institutions suggests these types of traumatic experiences can be examined in much the same way as abuse occurring within a personal relationship (Parnitzke, Smith, \& Freyd, 2014). The necessity of an institution may create an unavoidable dependency as well. For instance, trafficking victims needs can only be met through law enforcement, after care, and health care services. Betrayal may be actively committed or it may occur via omission of protective, preventative, or responsive actions (p. 579). For example, under U.S. law, victims are not to be held in detention facilities or charged with crimes underlying a trafficking offense, but that is not always upheld (Logan, Walker, \& Hunt, 2009). The secondary betrayal human trafficking victims' experience, when the very institutions that are supposed to help them do not, worsens the existing trauma.

When a trafficked person is seemingly involved in illegal activities such as prostitution, it may be difficult to define them as victims if law enforcement does not look past the criminal 
activity to see if it is human trafficking (Logan, Walker, \& Hunt, 2009). This is compounded by the fact that some may not appear to be victims, especially if they are not physically restrained (Farrell \& Fahy, 2009). Domestic trafficking victims have been misidentified as prostitutes in Illinois and Florida (Nichols \& Heil, 2014), and because of the initial incorrect assumption and misreporting, their victimization was not "deemed worthy of federal prosecution" as human trafficking cases (Heil, 2012, p. 57). Now the victim has been trafficked, labeled a criminal, and denied help. Prostitution is regularly viewed as a victimless crime, thereby denying the humanity of the women and girls involved; it is not believed they are capable of being hurt or raped and are usually seen as willing participants who have "asked for it" (Lloyd, 2012, p. 127). One of the problems with this misconception is that it leads to victims being charged with prostitution. They are criminalized for what has been done to them; the victim, who has been beaten, raped, and used to make money, is treated as the criminal while the trafficker remains free. They are shown nothing but disdain, then law enforcement wonder why they are resistant or do not seem to want help (p. 137). Rachel Lloyd, a trafficking survivor and founder of Girls Education and Mentoring Services (GEMS) states, "It is difficult to view yourself as a victim, no matter what happens to you...when those who are supposed to protect you see you as incapable of being victimized" (p. 126).

Another form of institutional betrayal is withholding services due to investigation and prosecution policies. Government protection and benefits are conditional; services are only offered if (1) the victim is willing and able to report the crime, and (2) if law enforcement subsequently agrees to investigate it as a human trafficking offense (Logan, Walker, \& Hunt, 2009). Victims are often reluctant to fully cooperate with investigations due to trauma, fear of retaliation by their trafficker, and fear of the police, especially in the beginning (Farrell \& Fahy, 
2009, p. 624). This means victims are often denied support even though it has been found such services are mutually beneficial to prosecution and victims, as victims are more likely to be available and cooperate while receiving after care (Nichols \& Heil). Moreover, even if a victim fully cooperates, the decisions to not investigate it and/or not prosecute it as a human trafficking case are still possibilities. Without all three elements of force, fraud, and coercion clearly represented, many prosecutors choose not to pursue trafficking cases - despite the fact that the law states it is necessary to prove only one of the three (p. 13). However, when misreporting occurs and the case is not identified as human trafficking, there is a failure of law enforcement to gather evidence that proves force, fraud, or coercion (p. 26). Therefore, the initial misreporting and investigation can have dire consequences for the prosecution. It is not just victims who see this vicious cycle; victim service providers are also hesitant and, in some cases, unwilling to alert law enforcement about victims out of fear the victims will be further harmed by the criminal justice process, particularly if they do not fit the image of the young, innocent trafficking victim usually depicted in the media (Farrell \& Fahy, 2009).

The prosecution of traffickers is too frequently based solely on the victim's cooperation and testimony, which places the burden on the victim rather than the investigators. Victims are not always willing to testify initially, largely due to lack of victim protection and services (Nichols \& Heil, 2014). Despite how difficult it is to have victims who are already traumatized and extremely fearful, to testify against their trafficker (Hounmenou, 2012), only victims under 18 are deemed too vulnerable to testify or cooperate in an investigation and prosecution (Logan, Walker, \& Hunt, 2009). However, double standards exist for underage victims as well. According to the TVPA, children and youth under 18 who are bought and sold for sex are victims of a severe form of trafficking and it is not required to prove force, fraud, or coercion 
(Lloyd, 2012). While this directive is followed with international victims, it is often overlooked when the victims are domestic. If an underage victim from anywhere in the world is found in a brothel in Queens, they are eligible for services provided and funded by the TVPA; they are taken to a safe house, given counseling for trauma, and treated as a victim - as they should be. Conversely, if the victim is American, he or she is arrested, charged with prostitution, and taken to juvenile detention (p. 139).

In addition to labeling victims as criminals, withholding after care services, misreporting, and problems with prosecution, there are also indications of problems with police officers reporting an incident at all (Nichols \& Heil, 2014). Police and prosecutors routinely discourage reporting or filing charges when faced with sexual assault cases that are difficult to prove or prosecute (Campbell, 2006; Campbell \& Raja, 2005) so it stands to reason the same is true for human trafficking cases. According to U.S. Attorney Terry Kinney, trafficking cases are expensive, challenging, and generally unsuccessful, so most prosecutors prefer to pursue other charges that have higher chances for convictions (Hounmenou, 2012). The consensus is that trafficking cases are complex and protections are limited, making it difficult to prosecute traffickers and help trafficking victims.

\section{Trauma and After Care Services}

The mental health needs of human trafficking victims are usually more profound than physical ones due to intense psychological damage inflicted by traffickers (Zimmerman, Hossain, \& Watts, 2011). As previously discussed, some of the traumatic effects of trafficking include elevated depression, anxiety, PTSD, self-harm, memory loss, shame, mistrust of others, submissiveness to authority, social withdrawal, resignation, loss of self-esteem, guilt, loss of autonomy, suicidal ideation, and suicide (Hodge, 2014). The unhealthy cognitive adaptations 
also need to be worked out and will take time to repair. The additional secondary trauma of institutional betrayal further exacerbates this long list of effects.

\section{After Care Services}

Understanding the scope and impact of institutional involvement in traumatic events requires a willingness to examine ways in which trusted institutions may foster abuse, which may be uncomfortable (Jost, Banaji, \& Nosek, 2004; Smith \& Freyd, 2014). The role that the judicial system and after care programs play in liberating a human trafficking victim cannot be denied. Therefore, given this and the long list of traumatic after effects associated with trafficking and institutional betrayal, it is important that survivor-centered or trauma-informed approaches be taken when working with these victims.

Survivor and trauma centered approaches take vital information into account, such as: (a) Sometimes victims forget all or part of experiences; (b) Often victims do not disclose or do so only after a delay; sometimes disclosures are partial or incomplete as victims 'test the water' or have fragmented memories; (c) Victims may retract a legitimate accusation; and (d) Victims often display contradictory reactions including confusion, avoidance of social contact, flat emotions, anger, self-blame, and defending the perpetrator (Smith, Gomez, \& Freyd, 2014). Implementing these research-based tips often requires challenging common, but erroneous, knowledge or understanding of trauma (p. 465). It is important that investigators and after care providers understand that victims may change their stores, not tell complete stories, add to stories later, or give inconsistent statements, because disbelieving or blaming victims only compounds damage (Nichols \& Heil, 2014). Victims should have temporary care which includes health care, counseling, and shelter and not be held at detention facilities (Okech, Morreau, \& Benson, 2011). Also, services need to be available from the moment victims are identified to the point they are 
self-sufficient and in good psychological and physical health (p. 498). Moreover, these rights and protections should be available to all victims, regardless of cooperation in an investigation (Logan, Walker, \& Hunt, 2009).

After care programs are often the only resource for trafficking victims and the failure to respond appropriately can have damaging and long lasting effects. Most victims have nowhere to turn except service agencies (Zimmerman, Hossain, Yun, Gajdadziev, Guzun, \& Tchomarova, 2008). They usually walk away with nothing; they have no way to feed themselves, nowhere to live, and no transportation (Logan, Walker, \& Hunt, 2009). However, despite having greater needs, there are fewer resources and services for human trafficking victims than for victims of any other crime (Logan et al., 2009). The question is how to address the challenges trafficking survivors face with effective services and advocacy programs, and how to assist survivors in making successful transitions to "normal" life (Shigekane, 2007, p. 122).

A study has shown the importance of aftercare services that address survivors' changing needs as they move from initial freedom to recovery and independence (Macy \& Johns, 2011). Trafficking survivors have immediate needs, ongoing needs, and long-term needs, and Macy and Johns used this classification of needs to develop a framework for a continuum of aftercare services (p. 90). The seven core service areas are: (a) basic necessities; (b) secure, safe shelter and housing; (c) physical health care; (d) mental health care; (e) legal advocacy; (f) job and life skills training; and (g) substance abuse services. Macy and Johns also developed an after care service delivery framework, which they claim is the "best available evidence about after care services" (p. 95). According to this, providers should (a) begin with a comprehensive needs assessment; (b) continually work to ensure survivors' safety and confidentiality; (c) use traumainformed care practices; (d) provide comprehensive case management to coordinate all needed 
health, human, and legal services; (e) speak their language or provide translation services; (f) provide appropriate services; and (g) offer specialized housing (p. 96). Not only is the presence of these after care programs important, but also the functionality and effectiveness of these types of programs. This is why Macy and Johns focused not only on the needs of human trafficking survivors, but also how aftercare services can best meet these needs.

Additionally, Greene and Beinhart (2013) have discussed the need for evidence-based evaluations of anti-trafficking programs funded by the government in order to determine which programs are the most effective. Once this is known, other programs can follow suit. The only way to determine if services are effectively meeting survivor's needs is by assessing the programs and making improvements accordingly. Evidence-based evaluations, as well as measures to identify best practices and areas of improvement, would be helpful in assessing the effectiveness of survivor programs.

\section{Summary}

Human trafficking is an escalating problem affecting every country in the world, including the United States. The awareness campaigns and prevention efforts put forth by a variety of both organizations and individuals are impressive and not to be discounted. However, prevention is not enough. Having highly effective rehabilitation programs in place will help ensure survivors are able to have their specific needs met once they are liberated from this unimaginable horror; additionally, these programs should be in place in every state across the nation. Furthermore, in order to effectively prevent and respond to institutional betrayal systematically, it is necessary to incorporate training and education (Smith, Gomez, \& Freyd, 2014). Examining human trafficking through the lens of institutional betrayal further exemplifies 
why effective survivor programs are so important, as this betrayal exacerbates previous traumatic experiences. 
SECTION FOUR

\section{CONTRIBUTION TO PRACTICE}




\section{Type of Document}

I will request to present a Whitepaper Report to the Victim Advocacy Program Manager/Crime Victim Unit Division Manager and staff at the Missouri Sheriff's Association Training Academy in Jefferson City, Missouri. I will discuss my research and findings and elaborate on areas where the Victim Advocacy Program is excelling, as well as areas to be improved upon. I will discuss areas for further research and options that may further benefit human trafficking survivors involved with the Victim Advocacy Program. Any experienced institutional betrayal will also be discussed.

\section{Rational for Contribution Type}

The study aims to evaluate the effectiveness of the MSA Victim Advocacy Program in providing quality after-care services to human trafficking survivors that is absent of institutional betrayal.

\section{Outline of Proposed Contents}

The analysis of the study will include an introduction, a review of literature, summary of methods, summary of detailed findings from the interviews with human trafficking survivors and victim advocates, and summary of limitations and considerations for future research.

\section{Practitioner Document}

I plan to prepare a Whitepaper Report and present it to the MSA Victim Advocacy Program, specifically the Victim Advocacy Program Manager/Crime Victim Unit Division Manager and staff as they are the ones who oversee the program. This will be a white paper presentation addressing the effectiveness of the program in its current state. I will discuss the implications for research and possible improvements to increase effectiveness of the program and better meet survivor's needs. 


\section{Whitepaper Report}

\section{Introduction}

Human trafficking is an escalating problem affecting every country in the world, including the United States. Having effective after care services in place will help ensure survivors are able to have their specific needs met when they have escaped or been liberated from this unimaginable horror. Examining human trafficking through the institutional betrayal lens further exemplifies how trauma can be exacerbated in a number of ways when those who victims are dependent on for help, such as law enforcement or after care providers, do not and instead do more harm.

\section{Background}

Although there is a shared consensus on the cruelty and inhumanity of human trafficking, the question of what to do about it is proving difficult to answer. There are a number of articles addressing preventative measures and much emphasis is placed on increasing awareness, but that is not enough. Modern day slavery is happening; some is being prevented, but certainly not all. Survivors are in need of effective after care in order to help overcome trauma and successfully rebuild their lives.

Human trafficking is increasingly happening across the United States, including in Missouri and the neighboring states. Although recruitment of victims and selling of sexual services can easily take place anywhere in America, smaller cities in the Midwest have specifically been identified as high recruitment areas where traffickers manipulate and force youth into trafficking, then move them around to other cities throughout the country (Williamson and Prior, 2009). Prevention campaigns and awareness are not going to help once someone has fallen victim to trafficking. 
Focusing on human trafficking specifically through the lens of institutional betrayal helps illustrate the emotional and mental aftermath that survivors experience and how betrayal by trusted individuals and institutions may exacerbate traumatic effects. For instance, law enforcement officers are unfortunately a hindrance rather than a help sometimes, as are prosecuting officials who regularly charge traffickers with lesser offenses, to make it easier to secure convictions. Past literature also helps shed light on human trafficking and why this topic is important.

\section{The study}

This study used qualitative research to understand the experiences and perceptions of human trafficking survivors and Victim Advocates involved with the Victim Advocacy Program of the Missouri Sheriff's Association (MSA). The purpose of this study was to focus on human trafficking survivors and why effective survivor programs are necessary, to explore the survivor's experiences of institutional betrayal, and to focus on both survivors and Victim Advocate's perceptions of the program. After care services are vital to assisting human trafficking survivors through the aftermath of this traumatic ordeal and helping them rebuild their lives. Moreover, studying this trauma specifically through the institutional betrayal lens demonstrates the importance of effective after care services, as inadequate help only worsens traumatic effects. Furthermore, examining the challenges survivors face through this lens can help determine how effective these types of programs are, if or when institutional betrayal is occurring, and opportunities for improvement. Specifically, this study asked: RQ1: How do human trafficking survivors perceive after care services?; RQ2: How do the Advocates perceive after care services? 
Face-to-face, semi-structured interviews were conducted with five human trafficking survivors and six Victim Advocates who had relevant experience with the Victim Advocacy Program. Questions were open ended and participants were encouraged to talk as long as they wanted about each subject area. Interviews were audio-recorded and transcribed, with the transcripts of each interview being analyzed for codes then categorized into themes. All participants were assigned pseudonyms by the Crime Victims Unit (CVU) Division Manager prior to meeting the researcher. The researcher at no point throughout the study knew or had access to any of the 11 participant's actual names.

\section{Findings}

The results reveal the perceptions of five human trafficking survivors and six Victim Advocates, each of whom are affiliated with the Victim Advocacy Program. Results pertaining to each set of collected data are revealed according to specific content areas. The themes for human trafficking survivors include: program effectiveness, advocate helpfulness, experienced acts of institutional betrayal, and ideas for improvement. The themes for victim advocates include: program effectiveness, advocate responsibilities, and ideas for improvement.

\section{Human trafficking survivors}

Human trafficking survivors who had been involved with the program for at least six months were asked to participate in individual, face-to-face interviews. Of the human trafficking survivors asked to participate, six initially agreed to be interviewed for the study. However, upon arrival at the interview site, one of the participants changed her mind. Interviews were successfully conducted with five female survivors, between the ages of 19 and 27, who had been involved with the Victim Advocacy Program for various lengths of time, ranging from 11 months to more than four years. 
In terms of program effectiveness, all five human trafficking survivors shared the view that the Victim Advocacy program is highly effective. They each responded positively that the program made it easy to report their experiences, they received adequate and prompt responses, personal information and confidentiality was maintained, that their cases had been appropriately handled, and that their experiences (including those of institutional betrayal) were not covered up or denied in any way.

In regard to Advocate helpfulness, all five survivors reported each of their personal Victim Advocates were helpful throughout the process, from the initial involvement to the continuing care they are still receiving. They each indicated the Advocates helped them understand their rights, provided information about services and resources, and saw to it the survivors received services they needed. They also reported the Advocates were knowledgeable and easy to understand, and that none of the services the Advocates assisted with were nonhelpful.

In terms of institutional betrayal, each of the five survivors reported they had in fact experienced institutional betrayal. All instances involved law enforcement and/or prosecuting officials, and the experiences happened prior to survivor's involvement with the Victim Advocacy Program, as well as during the legal proceedings. However, one survivor's case was ongoing and, at the time of this study, official charges against the traffickers could not be confirmed. The other four survivors experienced a total of 11 acts of institutional betrayal between them, which included: two instances of law enforcement misreporting trafficking as prostitution; five instances of law enforcement disbelieving trafficking victims/turning victims away; two instances of prosecution charging traffickers with lesser offenses; and two instances of prosecution not charging traffickers at all. 
Table 1.

Institutional Betrayal Experienced by Human Trafficking Survivors

\begin{tabular}{|c|c|}
\hline Acts of Institutional Betrayal Committed & Instances of the Betrayal \\
\hline $\begin{array}{c}\text { Police Misreported Trafficking as } \\
\text { Prostitution }\end{array}$ & 2 \\
\hline $\begin{array}{c}\text { Police Disbelieved/Turned Away } \\
\text { Trafficking Victims }\end{array}$ & 5 \\
\hline $\begin{array}{c}\text { Prosecution Charged Traffickers } \\
\text { with Lesser Offenses }\end{array}$ & 2 \\
\hline Prosecution Did Not Charge Traffickers & 2 \\
\hline
\end{tabular}

When it came to ideas for improvement, each of the five survivors presented similar opinions of what would be helpful additions to the Victim Advocacy Program. The main, recurring ideas included a live-in recovery home, a separate human trafficking division, and offering group sessions/creating a survivor community. Two of the survivors expressed an understanding that funding would be an issue for the program and any new developments.

\section{Victim advocates}

Victim Advocates with at least one year of experience working in the field with human trafficking survivors were asked to participate in individual, face-to-face interviews. Of the victim advocates, six agreed to be interviewed. More initially expressed interest; however, time constraints made it difficult for more to be involved.

In terms of program effectiveness, all six Advocates are in agreement that the program is effective, from becoming involved with the program to the continued after-care and follow-up services administered. The method of reporting used, the confidentiality and personal information safeguards in place, and the steps for handling cases are all areas the Victim 
Advocacy Program prides itself on. While each advocate maintains a high level of program effectiveness, they also express a desire for growth and each share the view that things can always be improved.

In regard to Advocate responsibilities, they share the view of their responsibilities, including their role from the initial meeting to continued care and follow-up services. They understand the importance of adequately responding to victim's experiences and taking necessary steps to get each survivor the help he or she needs. They are also responsible for helping with past victimizations as well as victimizations that happened in another state, and assisting a victim without involving law enforcement.

When it came to ideas for improvement for the program, each of the six Advocates expressed a need, specifically, for greater funding above all else - as this is how to make additional services happen, which they agree is necessary. Similar to the survivor's responses, advocates identified the need for a live-in recovery home and a separate human trafficking division. They also expressed the need to grow the number of Victim Advocates across the state, and the need for increased trainings for police officers, medical staff, and others who are likely to come into contact with victims first.

\section{Conclusion}

This research study found that the participating human trafficking survivors and Victim Advocates perceive the after care services provided through the Victim Advocacy Program to be effective. Additionally, an absence of institutional betrayal within the program was made apparent. However, despite the efficacy of the program, survivors experienced acts of institutional betrayal both prior to and during their involvement with after care, specifically by law enforcement and prosecuting officials. The program improvement ideas put forth by survivors and Advocates 
indicated the need for a live-in recovery home for human trafficking survivors, as well as growing the Victim Advocacy Program across the state and increasing trainings for law enforcement officials and others who may come into contact with human trafficking victims. While these findings and conclusions may not reflect other after care programs or human trafficking experiences, these were the findings of this research study, which focused on the Missouri Sheriff's Association Victim Advocacy Program.

\section{Limitations}

Generalizability and transferability of data is one of the limitations of this study. Only human trafficking survivors in one program, in one state, are involved. The research findings of this study may not be an accurate representation of other programs in other areas as this study specifically evaluated a specific program, thereby limiting transferability (Creswell, 2012). This study cannot be duplicated in other settings with the expectation of similar findings. Additionally, the research data was collected in a shortened time frame and therefore is not as rigorous as a longitudinal design study (Creswell, 2012). Future research could delve deeper into the topic of survivors and after care services by studying several different programs, in other states, providing a more in-depth study of program effectiveness. 


\section{References}

Creswell, J.H. (2012). Qualitative inquiry \& research design: Choosing among five approaches ( $3^{\text {rd }}$ ed.). Thousand Oaks, CA: Sage.

Williamson, C. \& Prior, M. (2009). Domestic minor sex trafficking: A network of underground players in the midwest. Journal of Child and Adolescent Health Trauma, 2, 46-61. 
SECTION FIVE

CONTRIBUTION TO SCHOLARSHIP 


\section{Submission-Ready Journal Article}

I plan to submit my dissertation as a journal article to the Journal of Criminal Justice. I chose the Journal of Criminal Justice because it is an international journal intended to fill the need for the dissemination of information, ideas and methods in the criminal justice area. It focuses on various aspects of the criminal justice system and their ties to one another, and I think this is especially important when it comes to human trafficking. Various areas of law enforcement, legal offices, and after care service providers all have a part to play and strong working relationships are necessary to effectively tackle the issue of human trafficking and best meet survivor's needs. The author guidelines, provided online by the Journal of Criminal Justice, are as follows:

\section{Guide for authors .}

You may choose to submit your manuscript as a single Word or PDF file to be used in the refereeing process. Only when your paper is at the revision stage, will you be requested to put your paper in to a 'correct format' for acceptance and provide the items required for the publication of your article. To find out more, please visit the Preparation section below.

\section{Preparation}

It is important that the file be saved in the native format of the word processor used. The text should be in single-column format. Keep the layout of the text as simple as possible. Most formatting codes will be removed and replaced on processing the article. In particular, do not use the word processor's options to justify text or to hyphenate words. However, do use bold face, italics, subscripts, superscripts etc. When preparing tables, if you are using a table grid, use only one grid for each individual table and not a grid for each row. If no grid is used, use tabs, not spaces, to align columns. The electronic text should be prepared in a way very similar to that of conventional manuscripts (see also the Guide to Publishing with Elsevier). Note that source files of figures, tables and text graphics will be required whether or not you embed your figures in the text. See also the section on Electronic artwork. To avoid unnecessary errors you are strongly advised to use the 'spell-check' and 'grammar-check' functions of your word processor.

\section{Article structure}

Subdivision: unnumbered sections divide your article into clearly defined sections. Each subsection is given a brief heading. Each heading should appear on its own separate line. 
Subsections should be used as much as possible when cross-referencing text: refer to the subsection by heading as opposed to simply 'the text'.

- Introduction: State the objectives of the work and provide an adequate background, avoiding a detailed literature survey or a summary of the results.

- Discussion: This section should explore the results of the work. A combined Results and Discussion section is often appropriate. Avoid extensive citations and discussion of published literature.

- Conclusions: The main conclusions of the study may be presented in a short Conclusions section, which may stand alone or form a combined Discussion and Conclusions or Results and Conclusions section.

\section{Essential title page information}

- Title: The title of the article should be included on page 1 (eighty spaces maximum). Titles are often used in information-retrieval systems and should be concise and informative. The title of your article must be clear and descriptive, using words that are relevant to the subject area, and would most likely be used in an online search. Avoid abbreviations and formulae where possible. - Author names and affiliations. Where the family name may be ambiguous (e.g., a double name), please indicate this clearly. Present the authors' affiliation addresses (where the actual work was done) below the names. Indicate all affiliations with a lower-case superscript letter immediately after the author's name and in front of the appropriate address. Provide the full postal address of each affiliation, including the country name, and, if available, the e-mail address of each author.

- Corresponding author. Clearly indicate who will handle correspondence at all stages of refereeing and publication, also post-publication. Ensure that telephone and fax numbers (with country and area code) are provided in addition to the e-mail address and the complete postal address.

- Present/permanent address. If an author has moved since the work described in the article was done, or was visiting at the time, a "Present address" (or "Permanent address") may be indicated as a footnote to that author's name. The address at which the author actually did the work must be retained as the main, affiliation address. Superscript Arabic numerals are used for such footnotes.

\footnotetext{
Abstract

Authors should provide a structured abstract which should be no more than 200 words in length. The structured abstract should succinctly state the purpose of the study, basic procedures, most important findings, and principal conclusions, with an emphasis on the new aspects of the study. An abstract is often presented separately from the article, so it must be able to stand alone. For this reason, references should be avoided, but if essential, then cite the author(s) and year(s). Also, non-standard uncommon abbreviations should be avoided, but if essential they must be defined at their first mention in the abstract itself. An example of the structured abstract is:

Purpose:

Methods:
} 
Results:

Conclusions:

\section{Keywords}

Immediately after the abstract, provide a maximum of 6 keywords, using American spelling and avoiding general and plural terms and multiple concepts (avoid, for example, 'and', 'of'). Be sparing with abbreviations: only abbreviations firmly established in the field may be eligible. These keywords will be used for indexing purposes.

\section{Contact Details for Submission}

Submission to this journal proceeds totally online and you will be guided stepwise through the creation and uploading of your files. The system automatically converts source files to a single PDF file of the article, which is used in the peer-review process. Please note that even though manuscript source files are converted to PDF files at submission for the review process, these source files are needed for further processing after acceptance. All correspondence, including notification of the Editor's decision and requests for revision, takes place by e-mail removing the need for a paper trail.

\section{Plan for Submission}

I will submit the article for publication upon the successful defense of my dissertation, target date in March of 2017. I will create an online account to submit the completed manuscript for online review. 
Human trafficking survivors, after care services, and institutional betrayal:

A qualitative perspective on the effectiveness of a victim advocacy program

Jodi L. Williams, Ed.D.

University of Missouri-Columbia 105 Jesse Hall

Columbia, MO 65211

United States of America

(573) 651-5910

jlwfhc@mail.missouri.edu

jlwilliams@semo.edu 


\begin{abstract}
This article is derived from a qualitative study designed to evaluate the effectiveness of the Missouri Sheriff's Association Victim Advocacy Program in rehabilitating human trafficking survivors. Face-to-face, semi-structured interviews with survivors and Victim Advocates affiliated with this program provided multiple perspectives which supported and enhanced data collection through thick, rich descriptions. The conceptual framework for this study included betrayal trauma theory and institutional betrayal. Betrayal trauma theory expounds on the posttraumatic effects of trauma on persons when betrayal occurs in an attachment relationship; the concept of institutional betrayal builds on this theory and outlines the significance of an institution betraying an individual who trusts or depends upon that institution just as they would another person (Parnitzke, Smith, \& Freyd, 2014).

Data collected from interviews provided a more thorough understanding of human trafficking survivors and Victim Advocates and was coded for consistencies and emerging themes. The findings indicated the Victim Advocacy Program is beneficial, but Advocates and survivors agree improvements can and should be made. Additionally, it was found that institutional betrayal, specifically related to law enforcement and prosecuting officials, existed. This data increases the understanding of human trafficking, institutional betrayal, and why effective after care services are crucial.
\end{abstract}

\title{
Keywords
}

After Care Services; Human Trafficking; Institutional Betrayal; Misreporting; Survivor; Victim 


\section{Introduction}

Human trafficking is a growing problem nationwide with no clear cut solutions. There is a lot of emphasis placed on the importance of prevention campaigns, as well on increasing awareness. Although both of these concepts are important, neither are enough, and neither are helpful to survivors of human trafficking who need help after it has happened.

Focusing on trafficking survivors and the psychological trauma they experience helps exemplify what is meant by human trafficking and why effective survivor programs are necessary. While preventative measures are important, more needs to be done for those that prevention methods are not going to help; the survivors. After care services are vital to assisting human trafficking survivors through the aftermath of this trauma and helping them rebuild their lives. Moreover, studying this trauma specifically through the institutional betrayal lens demonstrates the importance of effective after care services, as inadequate help only worsens traumatic effects. For the purpose of this study, there is a difference between the terms 'victim' and 'survivor'. Anyone who has been trafficked has been a victim, and the ones trapped in a trafficking situation remain victims, and will be referred to as such. The term survivor refers to those who have been liberated and denotes life after trafficking.

Researching and describing the lived experiences of survivors themselves through the specific lens of institutional betrayal creates a clearer picture of what being a human trafficking survivor entails, and the betrayal that some may experience at the hands of those entrusted to help, further indicating why effective rehabilitation is crucial. Liberation from trafficking is only the beginning for a survivor; recovery is a long road and often those responsible for providing much needed support to survivors do just the opposite. Research has shown that institutions can cause additional harm to assault survivors (Smith \& Freyd, 2013). Examining what part after 
care services have played in survivor's reintegration can help determine how effective these types of programs are, as well as how they can be improved upon.

\section{Human Trafficking}

Human trafficking is not a term that is easily defined as there are many different types, ranging from indentured servitude to forced labor to sex trafficking. Human trafficking is defined by the Trafficking Victims Protection Act (TVPA) of 2000 as "the recruitment, harboring, transporting, supplying, or obtaining a person for labor or services through the use of force, fraud, or coercion for the purpose of involuntary servitude or slavery" (Logan, Walker, \& Hunt, 2009, p. 4). Additionally, sex trafficking is defined as occurring when a commercial sex act is induced by force, fraud, or coercion, or in which the person induced to perform sex acts is under 18 years of age, in which case it is not necessary to prove any of the three (p.4).

The key elements of the TVPA indicate it is illegal to exploit a person for profit or personal services (Logan, Walker, \& Hunt, 2009), but it is happening across the United States, including in Missouri and neighboring states. The use of coercion can be direct and physically violent, as most imagine it, or it can be through psychological means, which is more often the case. Moreover, people who have been trafficked have not given consent and even if there was initial consent, it has been rendered meaningless by the coercive, deceptive, or abusive means used by the trafficker (Shigekane, 2007). These working definitions successfully put human trafficking into terms that can be understood; however, they still do not fully convey what this violation of basic human rights entails.

\section{Institutional Betrayal}

Institutional betrayal occurs when an institution causes harm to an individual who trusts or depends on that institution (Parnitzke, Smith, \& Freyd, 2014). It is possible for a person to feel 
just as betrayed by an institution as they can by another person; this is because institutions, such as the military, often obtain the same high level of trust and dependency from their members that is common in relationships between people (Parnitzke, Smith, \& Freyd, 2013). This relationship to institutions suggests these types of traumatic experiences can be examined in much the same way as abuse occurring within a personal relationship (Parnitzke, Smith, \& Freyd, 2014). The necessity of an institution may create an unavoidable dependency as well. For instance, trafficking victims needs can only be met through law enforcement, after care, and health care services; betrayal may be actively committed or it may occur via omission of protective, preventative, or responsive actions (p. 579).

Institutional betrayal can include acts of commission, such as covering up information and having insensitive responses to disclosures of trauma (e.g. misreporting and victim blaming) or failing to prevent mistreatment (e.g. withholding services and not communicating victims legal options) (Smith, Gomez, \& Freyd, 2014). There are also indications of problems with police officers reporting an incident at all (Nichols \& Heil, 2014). When law enforcement incorrectly view human trafficking victims as perpetrators of crimes, such as prostitution, and when cases are not dismissed or diverted but sent deeper into the justice system, the cost is twofold: the traffickers are shielded from accountability and the real crime and trauma on the victim is not addressed (Williams, 2015). Further damage is done to victims when law enforcement officials and service providers fail to help them or directly do more harm. Human trafficking victims can be betrayed in a myriad of ways, intensifying traumatic experiences.

\section{After Care}

After care programs are often the only resource for trafficking victims and the failure to respond appropriately can have damaging and long lasting effects; most victims have nowhere to 
turn except service agencies (Zimmerman, Hossain, Yun, Gajdadziev, Guzun, \& Tchomarova, 2008). They usually walk away with nothing; they have no way to feed themselves, nowhere to live, and no transportation (Logan, Walker, \& Hunt, 2009). However, despite having greater needs, there are fewer resources and services for human trafficking victims than for victims of any other crime (Logan et al., 2009). The question is how to address the challenges trafficking survivors face with effective services and advocacy programs, and how to assist survivors in making successful transitions to "normal" life (Shigekane, 2007).

A study has shown the importance of aftercare services that address survivors' changing needs as they move from initial freedom to recovery and independence and includes each level of immediate needs, ongoing needs, and long-term needs (Macy \& Johns, 2011). Additionally, Greene and Beinhart (2013) have discussed the need for evidence-based evaluations of antitrafficking programs funded by the government in order to determine which programs are the most effective. The only way to determine if services are effectively meeting survivor's needs is by assessing the programs and making improvements accordingly. Evidence-based evaluations, as well as measures to identify best practices and areas of improvement, would be helpful in assessing the effectiveness of survivor programs.

\section{Victim Advocates}

The Missouri Sheriff's Association (MSA) actively worked to improve after care services

to crime victims by launching the Crime Victims Unit (CVU). The Victim Advocacy Program of the CVU strives to enhance the availability of immediate, comprehensive after care assistance to crime victims in all Missouri counties. This Victim Advocacy Program offers necessary advocacy services such as crisis intervention, transportation, support, and information about the criminal justice system ("MSA", 2015). As part of the CVU, Advocates of the Victim Advocacy 
Program are responsible for assisting Missouri law enforcement with providing enhanced victim services in the following ways: 1) Provide a response to the emotional and physical needs of crime victims, 2) assist primary and secondary victims and help stabilize their lives after victimization, 3) help victims understand and participate in the criminal justice process, and 4) provide victims with a measure of safety (MSA CVU Program Services, Policies, \& Procedures, 2013). Advocates also provide packets which include additional information, such as case processing and handling, what to do if threatened or intimidated, and contacts for future crises or emergencies ("MSA", 2015). Through the MSA CVU, Victim Advocates are doing what they can to ensure human trafficking survivors receive the assistance they need.

\section{Research Questions}

The research questions guiding this study are: 1 . How do human trafficking survivors perceive after care services? and 2. How do Victim Advocates perceive after care services?

\section{Conceptual/Theoretical Framework}

Betrayal trauma theory explains the unique posttraumatic aftereffects of traumatic experiences that involve betrayal as stemming from the maintenance of attachment relationships necessary for survival (Parnitzke, Smith, \& Freyd, 2013). Building on this theory is the concept of institutional betrayal, the framework of this study. Institutions often illicit similar trust and dependency from their members that is common in interpersonal relationships, meaning an individual can be betrayed by an institution just as they can by another person. Simply put, institutional betrayal occurs when an institution causes harm to an individual who trusts or depends on that institution (Parnitzke, Smith, \& Freyd, 2014).

When human trafficking victims reach out to law enforcement or disclose the truth to a service provider, they trust an institution enough to risk the real and imagined threats from 
traffickers in order to get help; but all too often, they do not receive it. Some victims have attempted to escape while in medical facilities, only to have health care providers disbelieve them entirely or discount their claims (Hodge, 2014). Similarly, police officers have rejected trafficking claims as false and some have sent victims back home with their trafficker following the "dispute" (p. 115). Examining human trafficking through this theoretical lens not only helps illustrate $t$ the secondary trauma associated with institutional betrayal, but also the importance of having high functioning after care services in place for survivors to rely on.

\section{Design}

This study used qualitative research in order to understand the lived experiences and perceptions of human trafficking survivors and Victim Advocates affiliated with the Victim Advocacy Program of the Missouri Sheriff's Association. Qualitative data were derived from face-to-face, semi-structured interviews with each survivor and victim advocate, individually and privately. Internal validity, the credibility of the results, was established by triangulation of the data through both multiple methods of data collection and multiple data sources (Merriam and Tisdell, 2016). The researcher verified what was said during the one-on-one interview with each survivor and Advocate against the observations and documents previously obtained by the Missouri Sheriff's Association, and also compared the findings to any past data collected.

\section{Setting}

This research study was conducted at the Victim Advocacy Program office of the Missouri Sheriffs' Association in Jefferson City, Missouri. This program is part of the Crime Victims Unit (CVU) and also serves victims of other violent crimes, such as domestic abuse and sexual assault. There are plans to develop a specific human trafficking division; at the time of this study, there was not a start date for that division. 


\section{Participants}

This study utilized a sample of five human trafficking survivors and six Victim Advocates, aged 18 or older, currently involved with the Victim Advocacy Program. The CVU Division Manager/Victim Advocate Case Manager assisted in the selection of participants; the survivors and Advocates were asked, confidentially and individually, if they would like to participate in the study. They were free to accept or decline without repercussion. Those who agreed to participate were assigned pseudonyms by the involved Manager; the researcher at no point throughout the study knew or had access to the eleven participant's actual names.

Human trafficking survivors who had been involved with the program for at least six months were asked to participate in individual, face-to-face interviews. Of the human trafficking survivors asked to participate, six initially agreed to be interviewed. However, upon arrival at the interview site, one of the participants changed her mind. Interviews were successfully conducted with five female survivors, between the ages of 19 and 27, who had been involved with the CVU Victim Advocacy Program for various lengths of time, from 11 months to more than four years.

Victim Advocates with at least one year of experience working in the field with human trafficking survivors were asked to participate in individual, face-to-face interviews. Of the Victim Advocates asked, six agreed to be interviewed. More initially expressed interest; however, time constraints made it difficult for more to be involved. Interviews were successfully conducted with six female Victim Advocates.

\section{Data Collection Tools}

This research study incorporated a qualitative design, with interviews being used as the primary method of gathering data. Fourteen interview questions addressed each survivor's human trafficking experience and subsequent involvement with the Victim Advocacy Program, any 
institutional betrayal encountered, whether or not the program is beneficial, how the program has helped or hindered them, and what areas could be improved upon. The interview protocol can be found in Appendix B. The 11 interview questions for Victim Advocates addressed each advocate's perception of after care services provided by the Victim Advocacy Program, advocate training and responsibilities, and ideas for program improvement and future growth. This interview protocol can be found in Appendix C.

Each interview started with conversational style introductions and informalities. The participants received an informed consent letter prior to the interview, found in Appendix A, and the researcher reviewed this information again before beginning the interview. Participants were reminded that participation is voluntary and anonymous, and that they can withdraw at any time. At the end of each interview, the researcher thanked the participant and asked permission to contact them again, in case further clarification was necessary. Each of the 11 interviews lasted approximately 30 to 45 minutes, was audio-recorded (after permission was granted), and any identifying information was omitted (Krueger \& Casey, 2009). All collected information will remain confidential in order to maintain privacy (Creswell, 2012; Merriam, 2009).

\section{Qualitative Analysis}

Interview transcripts were coded for consistencies and analyzed for emerging themes (Krueger \& Casey, 2009; Merriam, 2009). The aftermath each survivor experienced was examined through the lens of institutional betrayal, specifically focused on law enforcement and the Victim Advocacy Program officials. The researcher reviewed interview transcripts to ensure an understanding of interview data, as well as to ensure internal consistency (Krueger \& Casey, 2009; Merriam, 2009). The interviews were also analyzed using the comparison method known 
by Creswell (2014) as winnowing, which is the process of selecting the relative information to assist in the process of answering research questions.

\section{Limitations and Assumptions}

Generalizability and transferability of data is one of the limitations of this study. Only human trafficking survivors in one program, in one state, are involved. The research findings of this study is not an accurate representation of other programs in other areas as this study is specifically evaluating a specific program, thereby limiting transferability (Creswell, 2012).

One of the previously held assumptions before beginning this study was that institutional betrayal applies to human trafficking survivors. Given the number of different organizations and individuals a survivor comes in contact with, it is assumed that institutional betrayal is occurring at some level. A second assumption was that the Victim Advocacy Program does meet human trafficking survivor's needs. It was also assumed there were areas of the program that need to be improved upon, and/or new developments that need to be implemented in order to more effectively help survivors.

\section{Findings}

\section{Human Trafficking Survivors}

After a careful and expansive analysis and comparison of participant data among human trafficking survivors, four themes emerged: 1) program effectiveness; 2) advocate helpfulness; 3) experienced acts of institutional betrayal; and 4) ideas for program improvement.

\section{Theme 1: Program Effectiveness}

Research findings indicated all five human trafficking survivors perceive the Victim Advocacy Program to be effective. The key focus areas for program effectiveness include: ease of reporting, adequate and prompt responsiveness, case handling procedures, non-denial or 
discounting of trafficking experiences, confidentiality, after care and support services, and continued and future after care services. Each of these seven aspects convey program effectiveness as perceived by trafficking survivors.

When asked if there were difficulties with reporting, Melissa stated: "Nooo, they don't make it difficult to do anything!" There were also positive affirmations about the adequacy and promptness of the program's initial response to cases, such as Britney saying "Yeah, I mean the police called the Advocacy Program and someone was there before I was doing paperwork. That's pretty prompt." The use of positive language and examples was pervasive throughout each of the five interviews, from each survivor's initial involvement with the program to the continued care they are each still receiving.

Given the nature of trafficking, confidentiality is of utmost importance and this is another area where the Victim Advocacy Program excels. One survivor named Leah lightly said: “They use code words and all kinds of passwords; I probably couldn't even get into my own file!" For one survivor, Britney, confidentiality was the most important issue when she was making a decision to move forward, with the program and with testimony against her trafficker. She stated: “That was one of my biggest concerns, I'm worried about people finding out. But it's been almost a year and no one knows.” Each survivor proclaimed she feels safe and expressed certainty that no personal information is released.

All five survivors indicated the Victim Advocacy Program had met their needs for after care and support services throughout their involvement. Alice stated: "I have a job because of them and I still attend therapy and counseling sessions. They check up on me and I can call anytime or come here and meet with someone, even if my advocate isn't in." Leah also said: 
I went back to work a little over two years ago and they helped me with my resume, and we had pretend interviews so I'd be ready for that. I know they help with education here, too, like getting a GED and college paperwork.

The survivors confirmed the program plays an active role in assisting survivors from the beginning, and continues to make after care a priority into the future.

Finally, each of the five survivors also indicated the Victim Advocacy Program appropriately handled their cases and did not cover up or deny their experiences (including those of institutional betrayal) in any way. According to Alice: "It's because of them I understood what I needed to do to help convict my traffickers, and had the patience to wait it all out and go through with it." When asked if the program tried to cover up or deny any part of their experience in any way, responses were simple: one said "Not at all", two said "No", and two said "Nope". Each of the survivors experienced institutional betrayal at some point, but they were quick to point out if was who not the Victim Advocacy Program that mishandled their case and/or denied their trafficking experience, as Leah stated: "The police mishandled it the first time, but not them." Alice also added: "Other than my first encounters, when three different police officers treated me as nothing more than a deranged woman running through the streets, the program and law enforcement have been understanding... and pursued a case against the traffickers." Melissa also said "Oh no, it's not their fault the charges aren't good enough, that the police didn't believe me at first. They did everything they could." Britney further added: "If anything, she wanted me to tell her more; she wanted every detail, told me to call her anytime of the day if I remembered something else. She wants to make sure the police have everything." These responses indicate that not only does the Victim Advocacy Program appropriately handle cases and want to ensure the legal cases against traffickers are moving forward, they are also 
working to ensure survivor's voices and experiences are heard and that institutional betrayal is not happening within the program.

\section{Theme 2: Advocate Helpfulness}

Research findings indicated that Advocates of the Victim Advocacy Program are perceived as helpful and knowledgeable, as all five survivors positively affirmed their abilities. The focus areas for helpfulness include: understanding of rights, information about services and resources, services utilized, non-helpful services, and effective communication. These five aspects accurately conveyed advocate helpfulness.

Survivors indicated the Advocates helped them understand their rights, and assured them it was not their fault this had happened. Melissa stated: "She made sure I knew it wasn't my fault, that I could press charges, testify ya know, do something about what had been done to me." Leah also reflected:

She's good at talking to you, not at you. She didn't tell me to do anything, didn't say I had to testify, that I had to go to counseling... she just talked about what may be helpful, the benefits. Everything was my decision.

Findings indicated this style of help is what Advocates rely on, rather than telling survivors what to do or trying to make them testify.

In regard to the after care services and resources available, survivors indicated the Advocates provided adequate information and, more importantly, saw to it that survivors received help. Alice stated: "They helped me get housing, provided counseling - I'm still in that - transportation to and from court...and when I was ready, the resources I needed to get a job." Heather, who had previously lived at a recovery home for trafficking survivors in another state, offered a different perspective: 
I came in and kinda jumped to the end - I had done the counseling and classes and all that for two years already, but I needed help moving forward and figuring out what to do next, now that I was back in the real world. I earned my GED at the recovery home, but my advocate here helped with paperwork for college and with volunteer opportunities.

Whether it is initial help with housing or college planning, the findings indicated the Advocates are knowledgeable about resources, and ensure survivors receive assistance.

In order to ascertain if there were steps the Advocates could eliminate or improve upon in their practice, this research also focused on what, if any, services were not helpful. However, survivor's perceptions of Advocates indicated they did not find anything to be non-helpful; survivors also indicated that even if something was not helpful to them, it may be to someone else. Heather stated: “I think everything they do is helpful, even if you don't utilize it. Someone like me, I've been through counseling since I lived at the recovery home, so I didn't need the initial services...but they still went over everything." Alice elaborated further:

I think everyone is different, what is helpful to one may not be to another. Several don't seem to like "court" stuff because they don't want to be involved with that, they just want to move on. So...it's not helpful to them. But to say it's not helpful? I don't agree with that.

The other three survivors also indicated they do not consider any services to be non-helpful. Effective communication was the final aspect of advocate helpfulness, and findings indicated that survivors perceived the Advocates as easy to understand and talk to. Alice stated: "They all know their stuff and are here to help. You can call anytime, day or night, and they will help with whatever you need." Heather stated: "I had a water issue and a plumber had to come...well having a strange man in my apartment, that's a different experience for me. She 
talks to me when stuff like that happens, or if I'm having a bad day." Findings indicated that each survivor relies on her advocate on a regular basis, for assistance with job interviews to discussing a bad day.

\section{Theme 3: Experienced Acts of Institutional Betrayal}

The findings indicated that each of the five human trafficking survivors experienced some form of institutional betrayal. One of the survivors was turned away by three police officers in one night when attempting to report human trafficking; one survivor's report was never investigated; and two survivor's cases were initially misreported as prostitution. Only one of the five survivors was treated as a human trafficking victim from the beginning, as she was found when police officers conducted a trafficking raid.

The acts of institutional betrayal continued past the initial involvement with law enforcement for the survivors, as their traffickers were not charged at all or charged with lesser offenses than trafficking. Melissa stated:

They had me and four other girls, all saying the same thing, and they kept talking about prostitution...I mean, I didn't know about trafficking then yet either. I just knew we were getting raped and that couple was getting paid. None of us were more than 19, but that one being 16, that's what got 'em.

The couple that trafficked her and four other girls were charged with one count of pimping and pandering, and only in connection with the minor they had in custody. They are not facing any trafficking charges, nor any charges in connection with Melissa or the other two females who were found locked in a hotel room with them, despite Melissa's testimony.

Leah's case started out similar, as it was misreported as prostitution, but police kept investigating and discovered a trafficking ring two men were running out of an apartment 
complex. She stated: “I don't think I should have had to wait for months, but at least it happened. And they were both charged with trafficking. One only served a year but the main guy, he got 20 years." Alice was the only other survivor who got to see her traffickers go to prison, after being ignored and sent away by three police officers in a matter of hours when she initially escaped and attempted to report. She stated:

Literally, I took off down the street in a nightie and no shoes - I went to the police station but he didn't believe me and turned me away. He told me it was perfectly "safe" for me to go back on the streets with no money or I.D., nowhere to go, nothing.

After approaching two other police officers on the street, who also disbelieved her and refused to help, Alice still clung to hope and returned to the police station a few days later, and this time the officers listened. "The whole thing took years...them getting charged, going to court, then finally going to jail. They didn't get all of them though."

For Heather, the institutional betrayal was simple: law enforcement, to this day, have never investigated her case. It has been over two years since she reported; to her knowledge, her trafficker was never questioned. Heather said: "I gave the police his description, what happened...my parents picked me up and went with me. We called, a lot in the beginning, to see what was happening. I was basically told it was my word against his." Heather has decided that while she likes the idea of testifying and him going to jail, she doubts that will happen at this point and just wants to move on with her life. She has stopped calling for updates and no one at the police station has ever called her.

Britney was the survivor found in the trafficking raid and the prosecution and court process is still ongoing; however, she has already been warned the traffickers may be prosecuted for lesser charges, despite her testimony. Britney stated: "Everyone keeps reminding me it's hard 
to prove it's like, I guess for sure trafficking. She [her advocate] wants me to...I don't know, be prepared for that. In case.” Britney was the only survivor whose case was at this early stage and she has been told it may be months before they move forward. All instances of institutional betrayal experienced by the five survivors involved law enforcement and prosecuting officials; none of the survivors reported any acts of institutional betrayal by the Victim Advocacy Program.

\section{Theme 4: Program Improvement}

The findings indicated the five survivors had similar ideas for improving the Victim Advocacy Program. A long-term, live-in recovery home was mentioned specifically by all five; an independent human trafficking division (separated from the other crime victims the program serves) and facilitating group sessions/survivor community were the other top two recurrent ideas. This type of survivor-informed approach is important, as it takes into account the survivor's perspectives of what makes for effective after care.

A live-in recovery home for human trafficking survivors was specifically mentioned by all five survivors. Heather's previous stay at a recovery home allowed her to see firsthand the differences between a live-in facility and what the Victim Advocacy Program offers, and she stated:

I think the best thing this program could do is have a live-in recovery home, like the one where I stayed. It's like you're in outpatient care from the beginning here and that may not be enough. Having a stable, constant environment was a big help in my recovery classes and counseling, group, dinner, even activities - they were all where I lived.

Other survivors echoed her views, without ever stepping foot in a live-in recovery home. Melissa stated: "That other city had a place for victims to stay, to live, and I think that's a good thing. I 
know they set up housing, but I don't know...having to live alone... seems rough.” Britney pointed out another aspect as well: 'I would like to like to talk to other girls. I just don't have anyone except my advocate. And my counselor. They understand, but not really. Because it didn't happen to them." A live-in recovery home was the unanimous, number one improvement idea.

The findings indicated the survivors had a grasp on financial concerns associated with a live-in facility and had other options for consideration as well. Alice stated: "I think just having a division that focuses only on human trafficking would be an improvement, more specialized care and structure." Some survivors also expressed discomfort at seeing victims of other crimes, or more accurately, victims of other crimes seeing them. Britney explained: "I would like it better if everyone I see had been through what I had. They help victims of other crimes... and that's good...but I wish there were a different area, just for us." A division of services with distinct offices may create a more comfortable space not just for trafficking survivors, but for everyone involved with the Victim Advocacy Program.

Lastly, the findings indicated that survivors would like opportunities to meet and talk amongst themselves. While they agree that no one should be forced to join a group session or meet if they do not want to, several of the survivors think it should be an option. Leah was the most in favor of this idea and stated:

I just think it would be helpful, for those of us who want to talk to others who've been through it, too. Then I think there could be more activity based things from there, things we could do together. I mean, counseling is great, but I've heard about other programs that have paint nights and actually do stuff together and I think you need that kind of thing, too. 
Melissa also stated: “Group sessions, where survivors talk if they're ready - no one makes you or anything. I think that sounds good. I think talking is helpful...so to talk to other ladies who've been there would be nice." The findings indicated an interest, from all survivors, to talk to other human trafficking survivors as a way of healing and working together.

Despite the survivor's enthusiasm with discussing opportunities for improvement, the financial issues associated with such endeavors were not forgotten. Two of the survivors explicitly stated that funding would be an issue for any improvement plans at the Victim Advocacy Program. This sentiment was steadfastly echoed by the six Advocates as well.

\section{Victim Advocates}

From the victim advocate data, three themes emerged: 1) program effectiveness; 2) advocate responsibilities; and 3) ideas for program improvement.

\section{Theme 1: Program Effectiveness}

Research findings indicated all six Victim Advocates perceive the Victim Advocacy Program as effective. The key focus areas for effectiveness include: method of reporting and initial involvement, confidentiality, crime victims assisted, current and continued after care services, and meeting survivor needs. Each of these five aspects convey program effectiveness as perceived by trafficking survivors.

From the moment of initial involvement and reporting to the continued after care and follow up services the program offers, the Advocates maintained the program is designed to meet human trafficking survivor's initial and long-term needs as effectively as possible. Kelly stated:

As human trafficking is an emerging crime, our program has been instrumental in securing and supporting services for survivors across the state. In addition, we have invested time into training law enforcement to understand the dynamics and emerging 


\section{data around this crime.}

Advocates also said existing as a resource for survivors, being educated about human trafficking, being active in the anti-trafficking movement, and being up to date on best practices helps the program to best meet survivor's needs. Erin stated: "Linking victims to existing resources, supporting them throughout their healing journey, assuring their rights are being respected during prosecution - if they move forward - these are all steps the program has in place that ensures effectiveness on multiple levels."

A survivor's initial involvement with the Victim Advocacy Program is viewed as highly important and the program has specific steps in place. Andrea stated: "We have intake forms, we record client information, specific victimization and other details that may be helpful. If a victim knows they want to press charges and testify, we're a connection between them and law enforcement." Kelly also said: "Advocates maintain files with descriptions of each case. Services can be provided to all jurisdictions across the state so we keep in house records of contacts and meetings that aren't kept with the case files in the individual offices." The program ensures procedures that best meet survivor's needs are in effect from the very start.

Confidentiality is another important aspect of the Victim Advocacy Program, and it is strictly maintained. Holly stated: "All survivor information in our offices is kept confidential and is closed to the public. Our team doesn't discuss anything survivor related outside our office." Jennifer also said: "All information is kept in locked and secure files and each computer requires a specific username and password. And it is up to the victim if they want to press charges, testify, anything that leads to public knowledge." While the program has confidentiality procedures and maintains the privacy of survivors in a multitude of ways, if a survivor testifies then it is a matter of public record. The program also has procedures in place for that aspect as 
well; Kelly stated: "We explain the court process and what it means for privacy - we explain this in detail to the survivors we are serving."

In regard to ensuring continued after care and follow up services, the findings indicated the Victim Advocacy Program was effective at ensuring these procedures as well. Erin stated: "Clients stay with the same advocate over the course of their time in order to provide continuity of care at all stages. The program itself, our offices, we're available $24 / 7$ to assist with whatever the survivor's current needs are." The program ensures continued services by remaining in contact with survivors (unless they request otherwise), checking in to make sure they are receiving necessary assistance, following up to ensure services (such as counseling) are working out, and having a visiting rotation to go see them daily, weekly, or monthly. Kelly said: "We are available to our survivors indefinitely. We have an automated electronic system that also alerts us to upcoming court hearings or special anniversary dates." The Victim Advocacy Program has designed strategies in order to meet trafficking survivor's short and long-term care needs as effectively as possible. While each advocate maintained the program is effective, they also expressed an interest in growth and the view that things can be improved upon.

\section{Theme 2: Advocate Responsibilities}

Although the Victim Advocacy Program has policies and procedures in place, the findings indicated that individual Advocates also feel a personal responsibility to do their job and effectively help survivors as much as possible. The focus areas for responsibilities include: advocate roles, ade3quate response to trafficking, past victimization, victimization outside the county/state, and involving law enforcement. Each of the five aspects convey what the advocates consider to be individual advocate responsibilities. 
The Advocates indicated their role includes assisting survivors through the criminal justice system, ensuring crime victims are aware of their rights, are being respected by police and officers of the court, linking survivors with resources such as counseling, shelter, and transportation, working to receive crime victims compensation, and generally assisting them with anything necessary. Jennifer stated: "Housing, transportation, court, counseling - any and every way we can assist, we do. I consider my role to be that of a very informative friend, holding their hand and helping in any way I can.”

The findings indicated that Advocates with the Victim Advocacy Program also work to ensure they are prepared to respond to survivor's experiences. Kathy stated: "Victim Advocates go through training and meet requirements, but we also attend mental health trainings, first responder trainings, you name it - most of us have done it. And we attend conferences and continue education.” Holly also said: “Advocates in our office are continuously going to trainings and keeping up with best practices in advocacy to ensure each victim is advocated for in the best way possible." Each advocate mentioned the required training, but each focused more on the outside trainings, workshops, and additional education they pursue on their own to more effectively do their job. As Jennifer stated:

A lot of the trainings are centered on meeting emotional and psychological needs. The road to recovery is long and people don't understand; it's like people think 'well they're not being trafficked anymore, it's over, they're fine'. Not true. The effects last long after and we understand that, we are always training to best help survivors.

Victim Advocates also heavily assist with survivors whose victimization occurred in the past, or in another city or county. The other Advocates agreed that helping survivors, regardless of the stage of victimization or location, was part of advocacy. Erin stated: 
We can support all victims whose crime took place in Missouri and we can help if it took place outside the state. If the victimization occurred in the past, we review what - if anysteps were taken previously and connect the victim to relevant resources like counseling or law enforcement if the victim is ready to take action in that way.

Advocates make referrals to other resources survivors need, encourage (but do not force) survivors to inform police, focus on how best to help the survivor move forward, identify if shelter and counseling are needed, and develop a plan of action based on the survivor and her needs. If the victimization happened in another location, the Advocates assist just like any other case but would advise the survivors to report where the victimization occurred as well. Andrea stated: "We would do whatever we could, and connect with the other city or county officials if the survivor wanted to move forward with a case." The Advocates also noted the additional difficulties of going through a court process in a different area than where you live. Kathy stated: "Sometimes things happen, it may be a college student or someone on vacation. I imagine someone needs more help with the legal process if they're navigating it from a different state, so we would do what we could." The Advocates share the opinion that if someone needs help, then they help them.

The findings indicated that while Victim Advocates encourage survivors to report to law enforcement, it is not required for assistance through the Victim Advocacy Program. Advocates confirmed that survivors can come in on their own and are sometimes referred from other sources such as shelters, other advocacy centers, and government agencies. Advocates also relayed that even if law enforcement officials bring a survivor in, she does not have to continue future interaction, as Erin pointed out: "A lot of people, even if they get here because of law enforcement finding them or bringing them here, don't want to press charges or anything like 
that, and that's fine." Several Advocates pointed out the 24 hour hotline the program offers, so anyone can contact an advocate at any time, no strings attached. Survivors are also free to discontinue involvement with law enforcement if they decide to. Andrea stated: "A lot of victims don't want to press charges, or change their mind once the process begins, and that's ok." Advocates convey the importance of pressing charges and testifying, but it is the survivor's decision to involve law enforcement or not; they receive the same after care services regardless.

\section{Theme 3: Program Improvement}

In regard to opportunities for growth and program improvement, the findings indicated a need for greater funding above all else. As Andrea stated: "The answer is simple - funding. Getting it, not so simple." The Advocates pointed out funding is necessary to make any improvements and additional services happen. Kelly also said: "There is a need to increase financial resources to continue to meet the needs of survivors." While the Advocates agree improvements are important, funding must first be in place.

Similar to the survivor's responses, Advocates identified the need for more survivor and victim-centered environments, such as a live-in recovery home and/or a separate human trafficking division. Jennifer stated: "We work with others to provide shelter but it would be great if we - the program - had a shelter, a live-in safe house with recovery and treatment options for survivors." Other Advocates voiced the same and mentioned similar healing programs, emergency programs, long-term recovery homes, and mental and emotional spiritual health programs to foster healing. Even a separate division would be an improvement, as Holly pointed out: "A program specifically designed for human trafficking survivors would be great, because their needs are different than survivors of other violent crimes." Advocates agreed that while a one-size-fits-all approach to victim advocacy is better than nothing, it could be better if 
the program had enough funding for several divisions for different crime victims. In the meantime, the Advocates mentioned the importance of working with other organizations, as Kelly stated: "We need to develop strong relationships with the agencies across the state and country that are meeting human trafficking survivor's needs." If a live-in recovery home or separate division cannot happen, referrals to places that do offer such services is in the best interest of survivors.

Advocates also expressed the need for additional Victim Advocates, as well as the need for increased trainings for police officers, medical staff, and others who are likely to come into contact with victims. Jennifer stated: "We don't have enough Advocates, we don't have enough money, we don't have enough resources. It's hard to grow this program across the state like we want when we don't have enough funding." Others voiced the importance of increasing the number of Advocates, growing the program to other locations, and having Advocates in every county. The trainings for law enforcement are also important, as evidenced by the acts of institutional betrayal the survivors experienced from police officers and prosecuting officials. Kathy also said: "We need increased trainings for police officers, highway patrolmen, emergency room staff - those who are likely to come into contact with victims first, so they know the signs." Advocates agreed providing trainings and education, staying informed about human trafficking, and increasing awareness will help ensure those who have contact with victims will be better able to recognize the signs of human trafficking and respond appropriately.

\section{Discussion and Conclusions}

The findings of this study provide interesting insights into the reality of human trafficking, institutional betrayal, and effective after care. This study contributes to the rather small body of literature on after care programs available for human trafficking survivors, and 
includes perceptions of program effectiveness based on actual survivors and Victim Advocates involved with a program. Moreover, this study makes an important contribution by examining human trafficking specifically through the lens of institutional betrayal, a topic on which little research exists.

\section{Human Trafficking Survivors}

Research question one asked how human trafficking survivors perceive after care services, specifically services offered through the Victim Advocacy Program. Findings indicated all five human trafficking survivors perceive the program as effective. Survivors reported no difficulty reporting and positive affirmations about the adequacy and promptness of the program. The use of positive language indicates each survivor's high regard for the program, from the beginning stages to continued care. All after care services are also provided regardless of a survivor's decision to press charges or move forward with a legal case. Confidentiality is of utmost importance and is another area where the program excels; each survivor proclaimed feelings of safety, knowledge that no personal information has been released, and confidence with security in place at the office.

The five survivors indicated the Victim Advocacy Program met their needs for after care services throughout their involvement. The program effectively assists with immediate needs such as shelter, transportation, and legal assistance; long-term needs such as resume building, job and interview training, and assistance with educational paperwork; and on-going care, such as counseling and living assistance. The survivors confirmed the program plays an active role in assistance from the start, and continues to make after care arrangements into the future.

Each of the five survivors also indicated the Victim Advocacy Program appropriately handled cases and did not discount their trafficking experiences, and allows time for the 
survivors to communicate what happened to them and share details of their ordeal. Each of the survivors experienced institutional betrayal, but it was not due to the Victim Advocacy Program. The Victim Advocacy Program appropriately handles trafficking cases, ensures legal cases against traffickers move forward (when applicable), ensures survivor's experiences are understood, and takes steps to ensure institutional betrayal is not happening within the organization, all of which help ensure program effectiveness.

The role that after care programs play in liberating a trafficking survivor cannot be denied. Therefore, it is important that survivor-centered or trauma-informed approaches be taken, as the Victim Advocacy Program is doing, based on the findings. These type of approaches take vital information into account, such as: (1) Sometimes victims forget all or part of experiences; (2) Often victims do not disclose or do so after a delay; (3) Victims may retract a legitimate accusation; and (4) Victims often display contradictory reactions (Smith, Gomez, \& Freyd, 2014). It is important that after care providers understand victims may change their stores, tell incomplete stories, add to stories later, or give inconsistent statements, because disbelieving or discounting will only compound damage (Nichols \& Heil, 2014). The Victim Advocacy Program also meets survivor's needs in ways previous studies have found to be crucial. For instance, Okech, Morreau, \& Benson (2011) found that victims should have temporary care which includes health care, counseling, shelter and not be held at detention facilities, and that services need to be available from the moment victims are identified until the point they are selfsufficient and in good psychological and physical health. It has also been found that rights and protection should be available to all victims, regardless of involvement in legal proceedings or an investigation (Logan, Walker, \& Hunt, 2009).

\section{Institutional Betrayal}


Each of the five human trafficking survivors experienced some form of institutional betrayal. One survivor was disbelieved and subsequently denied help by three police officers in the same night, one survivor's trafficking report was not investigated, and two survivor's cases were misreported as prostitution, despite their statements indicating trafficking. Of the five survivors, only one was rightfully identified and treated as a human trafficking victim from the beginning. The acts of institutional betrayal continued for three of the five survivors, as the traffickers were charged with lesser offenses than trafficking, or were not charged at all.

These findings were not surprising and indicate the problems of institutional betrayal that human trafficking survivors may face. As Nichols and Heil (2014) found, it addition to labeling victims as criminals, withholding after care services, misreporting, and problems with prosecution, there are also indications of problems with police officers reporting incidents at all. Furthermore, according to U.S. Attorney Terry Kinney, trafficking cases are expensive, challenging, and generally unsuccessful, so most prosecutors prefer to pursue other charges (Hounmenou, 2012). All instances of institutional betrayal experienced by the five survivors were directly related to law enforcement and prosecuting officials; none of the survivors reported institutional betrayal by the Victim Advocacy Program. As survivors rely on police and prosecutors for assistance, this type of institutional betrayal can be incredibly damaging to survivors. As Rachel Lloyd, a trafficking survivor and founder of Girls Education and Mentoring Services (GEMS) states, "It is difficult to view yourself as a victim, no matter what happens to you... when those who are supposed to protect you see you as incapable of being victimized" (p. 126).

It is also not uncommon for trafficking victims to be incorrectly misidentified and/or charged with prostitution. Domestic trafficking victims have been labeled as prostitutes in 
Illinois and Florida (Nichols \& Heil, 2014). Because of this incorrect initial assumption and misreporting, their victimization is not deemed worthy of federal prosecution as human trafficking cases (Heil, 2012). This is largely due to the fact that when misreporting occurs and the case is not immediately identified as human trafficking, there is usually not enough evidence gathered that proves it is trafficking (Nichols \& Heil, 2014). Furthermore, prostitution is regularly viewed as a victimless crime, thereby denying the humanity of the women and girls involved; it is not believed they are capable of being hurt or raped and instead seen as willing participants who have "asked for it" (Lloyd, 2012, p. 127).

\section{Victim Advocates}

Research question two asked how Victim Advocates perceive after care services offered through the Victim Advocacy Program; the findings indicated Victim Advocates perceive the program as effective. From initial involvement to continuing after care, the program secures services for survivors across the state. The program trains law enforcement on the aspects of human trafficking, exists as a resource for survivors, works to educate others about human trafficking, is active in the anti-trafficking movement, and stays up to date on best practices. The Victim Advocacy Program has designed strategies in order to meet trafficking survivor's shortterm, long-term, and ongoing needs as effectively as possible

A survivor's initial involvement with the Victim Advocacy Program is important and the program follows specific procedures. Intake forms, client information, victimization details, and whether or not law enforcement is involved and, if so, the connection the program will serve between survivors and officials is recorded. Confidentiality is also strictly maintained at the Victim Advocacy Program, with information kept confidential and in password protected files, stored in secure computers. 
The Victim Advocacy Program also ensures continued after care for survivors. The program does this by making continuing care plans for each survivor, remaining in contact with survivors, making sure necessary assistance is received, following up to ensure services are working out, and having a regular rotation wherein survivors are visited at home. The program also assists survivors with attaining education and job searches. The Victim Advocacy Program maintains effectiveness on multiple levels by linking survivors to helpful and necessary resources, supporting them throughout involvement, and ensuring their rights are respected by law enforcement and court officials.

Finally, the Victim Advocates themselves are a vital part of the Victim Advocacy Program as they have a multitude of responsibilities. Advocates assist survivors through the criminal justice system, ensure crime victims are aware of their rights and are being respected by officials, link survivors with resources including counseling, shelter, and transportation, and assist with anything else necessary. They are required to go through advocate training, but they also attend various outside trainings and pursue additional education, ensuring their own effectiveness as Advocates as well as the effectiveness of the Victim Advocacy Program.

Most survivors have nowhere to turn except service agencies (Zimmerman, Hossain, Yun, Gajdadziev, Guzun, \& Tchomarova, 2008); however, there are fewer resources and services for them than for victims of any other crime (Logan, Walker, \& Hunt, 2009). The Victim Advocacy Program and Advocates work to address the challenges trafficking survivors face by offering effective services and assist in any way possible to help survivors transition back into life, at their own pace. The program does this by focusing on survivors various needs on multiple levels; another study has shown the importance of doing just this - addressing survivor's changing needs as they move from initial involvement to recovery and independence 
(Macy \& Johns, 2011). Trafficking survivors have immediate, ongoing, and long-term needs, and Macy and Johns used this classification to develop a framework for a continuum of seven core after care services: (1) basic necessities; (2) secure, safe shelter and housing; (3) physical health care; (4) mental health care; (5) legal advocacy; (6) job and life skills training; and (7) substance abuse services. The Victim Advocacy Program offers services for survivor's immediate, long-term, and ongoing needs, all of which fit into this effective framework. Moreover, the program focuses on not only the needs of human trafficking survivors, but how the services provided can best meet their needs.

\section{Program Improvements}

The research findings indicated the five human trafficking survivors and six Victim Advocates had similar ideas for improving the Victim Advocacy Program. Survivors and Advocates identified the need for more survivor-centered environments, like a live-in recovery home and/or a separate human trafficking division. Survivors indicated a live-in facility would foster a more stable environment wherein all activities could take place, eliminating the need for travel back and forth. The opportunities for talking to other survivors and not having to live alone were also rationales for this improvement. Advocates share this view as it would better serve survivors to have a live-in safe house with recovery and treatment options on site. If not a live-in facility, then an inclusive human trafficking division, ensuring trafficking survivors do not have any interaction with the other crime victims, would be helpful in creating a more comfortable space at the Victim Advocacy Program. However, a live-in recovery home was the unanimous, number one improvement idea put forth by both survivors and Advocates.

Greene and Beinhart (2013) have discussed the need for evidence-based evaluations of anti-trafficking programs in order to determine which are the most effective. This addresses the 
fact that the only way to determine if services are effectively meeting survivor's needs is by assessing the programs and making improvements accordingly. While this study served as a way of gaining the involved survivor's and Advocates perceptions of the effectiveness of the Victim Advocacy Program, additional evidence based evaluations, and measures to identify best practices and areas of improvement would also be helpful in assessing the effectiveness of the program, now and in the future.

Despite the similarities between survivors and Advocates ideas, the Advocates also addressed the fact that funding is the first step to program improvement. The Victim Advocacy Program is currently in need of increased financial resources, so additional funding would be necessary for any future endeavors. The Advocates also consider opportunities for growth to be important areas for improvement, such as growing the number of advocacy offices across the state and increasing the number of Victim Advocates.

The Advocates also discussed the importance of trainings for law enforcement and others likely to have contact with human trafficking victims first. This makes sense, as other studies have found that when a trafficked person is seemingly involved in illegal activities, such as prostitution, or do not appear to be victims, law enforcement must know how to look past the assumed criminal activity or lack of restraints and see the signs of human trafficking (Logan, Walker, \& Hunt, 2009; Farrell \& Fahy, 2009). Additionally, the necessity of an institution creates an unavoidable dependency, and trafficking victims needs can only be met through law enforcement, after care, and health care services (Parnitzke, Smith, \& Freyd, 2014). Betrayal may be actively committed or it can occur via omission of protective, preventative, or responsive actions by law enforcement or other officials who come into initial contact with a trafficking 
victim, which indicates why adequate trainings are vital to ensuring survivors are correctly identified from the beginning, and the necessary after care services can promptly begin.

\section{Summary}

This research study found that the participating human trafficking survivors and Victim Advocates perceive the after care services provided through the Victim Advocacy Program to be effective. However, despite the efficacy of the program, survivors experienced acts of institutional betrayal both prior to and during their involvement with after care, specifically by law enforcement and prosecuting officials; there was no reported institutional betrayal by the Victim Advocacy Program. Additionally, the program improvement ideas put forth by survivors and Advocates indicated the need for a live-in recovery home for human trafficking survivors, as well as growing the Victim Advocacy Program across the state and increasing trainings for law enforcement officials and others who may come into contact with human trafficking victims. 


\section{References}

Creswell, J.H. (2012). Qualitative inquiry \& research design: Choosing among five approaches ( $3^{r d}$ ed.). Thousand Oaks, CA: Sage.

Creswell, J.H. (2014). Research design: Qualitative, quantitative, and mixed methods approaches. (4 $4^{\text {th }}$ ed.) Washington, D.C.: Sage.

Farrell, A. \& Fahy, S. (2009). The problem of human trafficking in the U.S.: Public frames and policy responses. Journal of Criminal Justice, 37, 617-626.

Greene, N.L. \& Beinhart, E. (2014). Combatting human trafficking - the U.S. government's response: A panel and a perspective on counter-trafficking in persons. ILSA Journal of International \& Comparative Law, 20(1), 49-84.

Heil, E. (2012). Sex slaves and serfs: The dynamics of human trafficking in a small Florida town. Boulder, CO: First Forum Press.

Hodge, D.R. (2014). Assisting victims of human trafficking: Strategies to facilitate identification, exit from trafficking, and the restoration of wellness. Social Work, 59(2), 111-118. doi: 10.1093/sw/swu002

Hodge, D.R. \& Leitz, C.A. (2007). The international sex trafficking of women and children: A review of the literature. Affilia, 22, 163-174.

Hounmenou, C. (2012). Human services professionals' awareness of human trafficking. Journal of Policy Practice, 11(3), 192-196. doi: 10.1080/15588742.655208

Krueger, R.A. \& Casey, M.A. (2009). Focus groups: A practical guide for applied research. Thousand Oaks, CA: Sage.

Lloyd, R. (2012). Girls like us: Fighting for a world where girls are not for sale. New York, NY: Harper Perennial. 
Logan, T.K., Walker, R., \& Hunt, G. (2009). Understanding human trafficking in the United States. Trauma Violence Abuse, 10(1), 3-30.

Macy, R.J. \& Johns, N. (2011). Aftercare services for international sex trafficking survivors: Informing U.S. service program development in an emerging practice area. Trauma Violence Abuse, 12(2), 87-98. doi: 10.1177/1524838010390709

Merriam, S.B. (2009). Qualitative research: A guide to design and implementation ( $3^{\text {rd }}$ ed.). Hoboken, NJ: Jossey-Bass.

Merriam, S.B. \& Tisdell, E.J. (2016). Qualitative research: A guide to design and implementation (4e). San Francisco: Jossey-Bass.

Missouri Sheriffs' Association. (2015). Retrieved from www.mosheriffs.com

Nichols, A.J. \& Heil, E.C. (2015). Challenges to identifying and prosecuting sex trafficking cases in the midwest united states. Feminist Criminology 10(1), 7-35. doi: $10.1177 / 1557085113519490$

Okech, D., Morreau, W., \& Benson, K. (2011). Human trafficking: Improving victim identification and service provision. International Social Work, 55(4), 488-503.

Parnitzke Smith, C \& Freyd, J.J. (2013). Dangerous safe havens: Institutional betrayal exacerbates sexual trauma. Journal of Traumatic Stress, 26, 119-124. doi: $10.1002 /$ jts. 21778

Parnitzke Smith, C \& Freyd, J.J. (2014). Institutional betrayal. American Psychologist, 69(6), 575-587.

Shigekane, R. (2007). Rehabilitation and community integration of trafficking survivors in the United States. Human Rights Quarterly, 29, 112-136.

Smith, C.P. \& Freyd, J.J. (2013). Dangerous safe havens: Institutional betrayal exacerbates 
sexual trauma. Journal of Traumatic Stress, 26, 119-124. doi: 10.1002/jts.21778

Smith, C.P. \& Freyd, J.J. (2014). Institutional betrayal. American Psychologist, 69(6), $575-587$.

Smith, C.P., Gomez, J.M., \& Freyd, J.J. (2014). The psychology of judicial betrayal. Roger Williams University Law Review, 19(45), 451-475.

Williams, T. (2015, July 9). History of abuse seen in many girls in juvenile system. The New York Times. Retrieved from http://www.nytimes.com

Zimmerman, C., Hossain, M., Yun, K., Gajdadziev, V., Guzun, N., Tchomarova, M. (2008).

The health of trafficked women: A survey of women entering post-trafficking services in Europe. American Journal of Public Health, 98(1), 55-59.

Zimmerman, C., Hossain, M., \& Watts, C. (2011). Human trafficking and health: A conceptual model to inform policy, intervention, and research. Social Science \& Medicine, 73, 327335. 
SECTION SIX

SCHOLARLY PRACTITIONER REFLECTION 
My dissertation has influenced my practice as an educational leader and scholar in ways I could not have predicted. Prior to my dissertation, I had completed a quantitative research study as an MBA student, but it was not as complex and rewarding as the dissertation process. Before that, I had only experienced small-scale research projects as part of course content. However, these early experiences proved to be great practice lessons for understanding and working with data and analysis that I came to rely on throughout the doctoral program. Even after two years of coursework focusing on data collection and analysis, and working on research projects implementing the knowledge, I could not have predicted the level of confidence I have with data and the data collecting process now that I'm finally at the completion stage of my dissertation.

At the completion of my dissertation, I realized my perspective has changed now that I am a leader capable of collecting and using my own data rather than being a leader who has to rely solely on other people's data. I feel I have always had an understanding of the importance of relevant literature and past studies and the impact those things can have on knowledge and decision-making abilities. While the literature review is a dreaded piece of work for some, I enjoy it. I have always looked forward to learning more about topics, and being able to use that knowledge to support my ideas and perspectives and tie concepts together. Now at the end of the dissertation process and having completed research, it was a happy realization that my work can be used by others to learn more about human trafficking, after care services, and institutional betrayal, and that it can aid in decision making and tying ideas and concepts together for other's research work as well.

This experience has allowed me to take on a different leadership role and use my own data collection and analysis to make important insights relevant to human trafficking and after 
care. This experience has also allowed for me to make recommendations for the Victim Advocacy Program of the Missouri Sheriff's Association; the Director and staff have gained insight and are able to make better informed decisions based on the results of my research on the program. I have been able to capture a glance of the future of the Victim Advocacy Program after hearing about the changes they are discussing, all brought about by my research. Being able to collect and analyze data for the purpose of making significant leadership decisions, and to help others make significant leadership decisions, is a powerful notion.

The dissertation process has influenced me as a scholar in much the same way it has affected me as a leader. Prior to my dissertation, I understood the importance of scholarship and appreciated other's research work and the contribution of knowledge to the field. However, most of my earlier experience in terms of contributing to scholarship was one sided; it was other people who contributed that knowledge and added to their fields of study, not me. Now, through my dissertation, I can see things from the other side and realize the benefits behind it as well. I have more confidence when it comes to collecting literature, reading, understanding ideas and forming concepts, and designing research for a specific purpose. Due to this increased level of understanding, knowledge, and confidence, I have an excitement to collect data; to figure out where to go next with my research into human trafficking and what connections I would like to make. While other's contributions will always be important and highly valued, I am thankful that I am now able and ready to make contributions through research endeavors of my own as well.

Throughout the dissertation process, I have gained confidence in my ability to increase understanding of human trafficking by analyzing past literature, making important connections between what is done versus what should be done and why, and designing 
research work that is aimed at providing insight to individuals and organization and, most importantly, improving the lives of human trafficking survivors. It is the idea that results from my research work have the potential to create positive change that gives me the most feelings of pride and accomplishment. Reflecting on this entire process, I am filled with gratitude that I have come so far in a relatively short amount of time and am now much better equipped to be an educational leader and contribute to scholarly work. 


\section{References}

Bolman, L. G., \& Deal, T. E. (2008). Reframing organizations (4th ed.). San Francisco, CA: Jossey-Bass.

Campbell, R. (2006). Rape survivors' experiences with the legal and medical systems: Do rape victim advocates make a difference? Violence Against Women, 12(1), 30-45. doi: $10.1177 / 1077801205277539$

Campbell, R. \& Raja, S. (2005). The sexual assault and secondary victimization of female Veterans: Help-seeking experiences with military and civilian social systems. Psychology of Women Quarterly, 29(1), 97-106. doi: 10.1111/j.14716402.2005.00171.x

Carr, A., Dooley, B., Fitzpatrick, M., Flanagan-Howard, R., Tierney, K., \& Egan, J. (2010). Adult adjustment of survivors of institutional child abuse in Ireland. Child Abuse \& Neglect, 34, 477-489. doi: 10.1016/j.chiabu.2009.11.003

City of Jefferson. (2014). Retrieved from www.jeffersoncitymo.gov

Clawson, H., Dutch, N., \& Williamson, E. (2008). National symposium on the health needs of human trafficking victims: Background brief. Washington DC: U.S. Department of Health and Human Services, Office of the Assistant Secretary for Planning and Evaluation.

The Covering House. (2013). Sex trafficking in the United States. Retrieved from Www.thecoveringhouse.org

Creswell, J.H. (2012). Qualitative inquiry \& research design: Choosing among five approaches ( $3^{r d}$ ed.). Thousand Oaks, CA: Sage.

Ehlers, A., Maercker, A., \& Boos, A. (2000). Posttraumatic stress disorder following political 
imprisonment: The role of mental defeat, alienation, and perceived permanent change. Journal of Abnormal Psychology, 109(1), 45-55.

Farrell, A. \& Fahy, S. (2009). The problem of human trafficking in the U.S.: Public frames and policy responses. Journal of Criminal Justice, 37, 617-626.

Fink, A.G. (2012). How to conduct surveys: A step-by-step guide ( $5^{\text {th }}$ ed.). Thousand Oaks, CA: Sage.

Greene, N.L. \& Beinhart, E. (2014). Combatting human trafficking - the U.S. government's response: A panel and a perspective on counter-trafficking in persons. ILSA Journal of International \& Comparative Law, 20(1), 49-84.

Gross, J. (1998a). Antecedent and response focused emotion regulation: Divergent consequences for experience, expression, and physiology. Journal of Personality and Social Psychology, 74, 224-237.

Gross, J. (1998b). The emerging field of emotion regulation: An integrative review. Review of General Psychology, 2, 271-277.

Healy, K. (2012). Remembering, apologies, and truth: Challenges for social work today. Australian Social Work, 65, 288-294. doi: 10.1080/0312407X.2012.705308

Heil, E. (2012). Sex slaves and serfs: The dynamics of human trafficking in a small Florida town. Boulder, CO: First Forum Press.

Hodge, D.R. (2014). Assisting victims of human trafficking: Strategies to facilitate identification, exit from trafficking, and the restoration of wellness. Social Work, 59(2), 111-118. doi: 10.1093/sw/swu002

Hodge, D.R. \& Leitz, C.A. (2007). The international sex trafficking of women and children: A review of the literature. Affilia, 22, 163-174. 
Hom, K.A. \& Woods, S.J. (2013). Trauma and its aftermath for commercially sexually exploited women as told by front-line service providers. Issues in Mental Health Nursing, 34, 7581.

Hounmenou, C. (2012). Human services professionals' awareness of human trafficking. Journal of Policy Practice, 11(3), 192-196. doi: 10.1080/15588742.655208

Jost, J.T., Banaji, M.R., \& Nosek, B.A. (2004). A decade of system justification theory: Accumulated evidence of conscious and unconscious bolstering of the status quo. Political Psychology, 25, 881-919. doi: 10.1111/j.1467-9221.2004.00402.x

Kim, K. (2007). Psychological coercion in the context of modern-day involuntary labor: Revisiting U.S. v. Kozminski and understanding human trafficking. University of Toledo Law Review, 38, 941-972.

Krueger, R.A. \& Casey, M.A. (2009). Focus groups: A practical guide for applied research. Thousand Oaks, CA: Sage.

Lloyd, R. (2012). Girls like us: Fighting for a world where girls are not for sale. New York, NY: Harper Perennial.

Logan, T.K., Walker, R., \& Hunt, G. (2008). Understanding human trafficking in the United States. Trauma Violence Abuse, 10(1), 3-30.

Macy, R.J. \& Johns, N. (2011). Aftercare services for international sex trafficking survivors: Informing U.S. service program development in an emerging practice area. Trauma Violence Abuse, 12(2), 87-98. doi: 10.1177/1524838010390709

McDonald, L., Beaulie, M., Harbison, J., Hirst, S., Lowenstein, A., Podnieks, E., \& Wahl, J. (2012). Institutional abuse of older adults: What we know, what we need to know. Journal of Elder Abuse \& Neglect, 24(2), 138-160. doi: 
$10.1080 / 08946566.2011 .646512$

Merriam, S.B. (2009). Qualitative research: A guide to design and implementation (3 ${ }^{\text {rd }}$ ed.). Hoboken, NJ: Jossey-Bass.

Merriam, S.B. \& Tisdell, E.J. (2016). Qualitative research: A guide to design and implementation (4e). San Francisco: Jossey-Bass.

Missouri Sheriffs' Association. (2015). Retrieved from www.mosheriffs.com

Nichols, A.J. \& Heil, E.C. (2015). Challenges to identifying and prosecuting sex trafficking cases in the midwest united states. Feminist Criminology 10(1), 7-35. doi: $10.1177 / 1557085113519490$

Northouse, P. G. (2013). Leadership theory and practice (6th ed.). Thousand Oaks, California: SAGE Publications, Inc.

Okech, D., Morreau, W., \& Benson, K. (2011). Human trafficking: Improving victim identification and service provision. International Social Work, 55(4), 488-503.

Palmer, N. (2010). The essential role of social work in addressing victims and survivors of trafficking. ILSA Journal of International \& Comparative Law, 17(1), 43-56.

Parnitzke Smith, C \& Freyd, J.J. (2013). Dangerous safe havens: Institutional betrayal exacerbates sexual trauma. Journal of Traumatic Stress, 26, 119-124. doi: $10.1002 /$ jts. 21778

Parnitzke Smith, C \& Freyd, J.J. (2014). Institutional betrayal. American Psychologist, 69(6), 575-587.

Raymond, J., D'Cunha, J., Dzuhayatin, S., Hynes, H., Rodriguez, Z., \& Santos, J. (2002). A comparative study of women trafficked in the migration process: Patterns, profiles, and health consequences of sexual exploitation in five countries (Indonesia, the Philippines, 
Thailand, Venezuela, and the United States). Belgium: Coalition Against Trafficking in Women.

Roby, J.L., Turley, J., \& Cloward, J.G. (2008). U.S. response to human trafficking: Is it enough? Journal of Immigrant \& Refugee Studies, 5, 508-525.

Shigekane, R. (2007). Rehabilitation and community integration of trafficking survivors in the United States. Human Rights Quarterly, 29, 112-136.

Smith, C.P. \& Freyd, J.J. (2013). Dangerous safe havens: Institutional betrayal exacerbates sexual trauma. Journal of Traumatic Stress, 26, 119-124. doi: 10.1002/jts.21778

Smith, C.P. \& Freyd, J.J. (2014). Institutional betrayal. American Psychologist, 69(6), $575-587$.

Smith, C.P., Gomez, J.M., \& Freyd, J.J. (2014). The psychology of judicial betrayal. Roger Williams University Law Review, 19(45), 451-475.

Smith, H.A. (2014). Walking prey: How America's youth are vulnerable to sex slavery. New York, NY: Palgrave Macmillan.

Williams, T. (2015, July 9). History of abuse seen in many girls in juvenile system. The New York Times. Retrieved from http://www.nytimes.com

Williamson, C. \& Prior, M. (2009). Domestic minor sex trafficking: A network of underground players in the midwest. Journal of Child and Adolescent Health Trauma, 2, 46-61.

Zimmerman, C., Hossain, M., Yun, K., Gajdadziev, V., Guzun, N., Tchomarova, M. (2008).

The health of trafficked women: A survey of women entering post-trafficking services in Europe. American Journal of Public Health, 98(1), 55-59.

Zimmerman, C., Hossain, M., \& Watts, C. (2011). Human trafficking and health: A conceptual 
model to inform policy, intervention, and research. Social Science \& Medicine, 73, 327335. 
Appendix A

\section{INFORMED CONSENT}

\section{PRINCIPAL INVESTIGATOR: Jodi L. Williams}

TITLE OF PROJECT: Human Trafficking Survivors, After Care Services, and Institutional Betrayal: A Qualitative Perspective on the Effectiveness of a Victim Advocacy Program

DURATION: The interviews will last approximately one hour.

PROCEDURES: Human trafficking survivor participants will engage in a qualitative interview process. Questions may include, but are not limited to the following: a) Did the Advocate help you understand your legal rights? b) How did the Advocate keep you (and your family) safe? c) Did the Advocate provide information about additional services and resources available to you? e) Was the Advocate knowledgeable and easy to understand? f) How could the Advocacy Program be improved?

A randomly assigned alias will be used to identify responses.

The Victim Advocacy Program Manager participant will engage in a qualitative interview process as well. Questions may include, but are not limited to the following: a) Describe the role of the Victim Advocate? b) How is confidentiality of victims maintained? c) What other crime victims does the Victim Advocacy Program assist? d) Describe how the program meets human trafficking survivor's specific needs? e) How do you think the program can more effectively meet human trafficking survivor's needs? f) Please describe the method of reporting through the Victim Advocacy Program?

POSSIBLE RISKS/DISCOMFORTS: Risks and/or discomforts are minimal.

POSSIBLE BENEFITS: The benefits to your participation are improvements to the Victim Advocacy Program of the Missouri Sheriffs' Association and an increased understanding of human trafficking, after care services, and institutional betrayal.

ALTERNATIVE PROCEDURES/TREATMENTS: There are no alternative procedures.

CONFIDENTIALITY: Every attempt will be made to see that your study results are kept confidential. The results of this study may be published and/or presented at meetings without naming you as a subject. Although your rights and privacy will be maintained, the Secretary of the Department of Health and Human Services, the College of Education IRB, and personnel particular to this research have access to the study records. Your responses will be kept completely confidential according to current legal requirements. They will not be revealed unless required by law, or as noted above.

CONTACT FOR QUESTIONS: If you have any questions about the research, your rights as a research subject, or problems at any time, you may contact Jodi Williams, researcher, or Dr. David Stader, research advisor. 
Jodi L. Williams

Southeast Missouri State University

One University Plaza

Girardeau, MO 63701

Phone: 573-344-0076

jlwilliams@semo.edu
Dr. David L. Stader

Southeast Missouri State University

One University Plaza

Cape Girardeau, MO 63701

Phone: 573-986-6944

dstader@semo.edu

VOLUNTARY PARTICIPATION: Participation in this research experiment is voluntary. You may refuse to participate or quit at any time. If you quit or refuse to participate, the benefits to which you are otherwise entitled will not be affected. You will be told immediately if any of the results of the study should reasonably be expected to make you change your mind about staying in the study.

By signing below, you confirm that you have read or had this document read to you. You will be given a signed copy of this informed consent document. You have been and will continue to be given the chance to ask questions and to discuss your participation with the investigator.

You freely and voluntarily choose to be in this research project.

PRINCIPAL INVESTIGATOR:

\section{DATE}




\section{Appendix B}

\section{Human Trafficking Survivor Interview Question Protocol}

Hello and thank you for taking time to participate in my study on the effectiveness of the MSA Victim Advocacy Program. Before we begin, I would like to briefly go over the informed consent form you previously received and returned. The interview will take less than an hour to complete and you have the right to stop the interview at any time. You also have the right to not answer certain questions. The purpose of my interview with you is to explore the your lived experience as a human trafficking survivor in terms of the after-care services provided by the Victim Advocacy Program. I will ask you a series of 14 questions and you may answer at any length you deem necessary. If I need clarification or further explanation about a response, I may ask follow-up questions. Participation in this interview will result in no more than minimal risk to you and the Victim Advocacy Program. Yours and other participant's identifying characteristics will remain completely confidential. Would you mind, for the purpose of accuracy, if I recorded the interview? You have the right to decline. Do you agree to participate in the interview? Thank you.

1. How did the Advocate help you understand your rights as a crime victim?

2. How did the Advocate help you understand your rights?

3. Did the Advocate provide information about services and resources that are available to you?

4. Which of these services did you utilize?

5. In your experience, are there services that are not helpful?

6. Is the Advocate knowledgeable and easy to understand?

7. What other services do you think the Victim Advocacy Program could provide to better 
assist human trafficking survivors?

8. Did the Victim Advocacy Program make it difficult to report your experience? If so, please explain?

9. Did the Victim Advocacy Program respond adequately and promptly to your experience?

10. Do you think the Victim Advocacy Program mishandled your case?

11. Did the Victim Advocacy Program try to cover up or deny your experience in any way?

12. Has the Victim Advocacy Program mishandled your personal information?

13. Has the Victim Advocacy Program met your needs for after-care and support services up to this point?

14. Is the Victim Advocacy Program continuing to make your after-care services a priority? 


\section{Appendix C}

Victim Advocate Interview Question Protocol

Hello and thank you for taking time to participate in my study on the effectiveness of the MSA Victim Advocacy Program. Before we begin, I would like to briefly go over the informed consent form that you previously received and returned. The interview will take less than an hour to complete and you have the right to stop the interview at any time. You also have the right to not answer certain questions. The purpose of my interview with you is to explore the functioning of the Victim Advocacy Program and its role in the after-care of human trafficking survivors. I will ask you a series of 11 questions and you may answer at any length you deem necessary. If I need clarification or further explanation about a response, I may ask follow-up questions. Participation in this interview will result in no more than minimal risk to you and the Victim Advocacy Program. Would you mind, for the purpose of accuracy, if I recorded the interview? You have the right to decline. Do you agree to participate in the interview? Thank you.

1. Please describe the role of the Victim Advocate?

2. Please describe the method of reporting victimization through the Victim Advocacy Program?

3. How is confidentiality of victims maintained?

4. What steps are taken to ensure Victim Advocates respond adequately to victim's experiences?

5. What other crime victims does the Victim Advocacy Program assist, other than human trafficking survivors?

6. If victimization occurred in the past, how does a Victim Advocate help?

7. How does the Victim Advocacy Program ensure continued after-care and follow up 
services are being administered?

8. Can the Victim Advocate still assist a victim if he or she was victimized outside their city or county?

9. Can someone report victimization and see a Victim Advocate without involving law enforcement?

10. In your own words, please describe how the Victim Advocacy Program meets human trafficking survivor's needs?

11. How do you think the program can more effectively meet human trafficking survivor's needs? 
VITA

Jodi was born in the small town of Kennett, Missouri to Steve and Joyce Williams. Jodi graduated from high school and immediately began her college career, graduating with a bachelor's degree in Business Administration in 2006 and a master's degree in Business Administration in 2010, both from Southeast Missouri State University.

Jodi became involved in human trafficking advocacy work in 2011, and underwent training at the Missouri Sheriff's Association in Jefferson City to be a licensed Victim's Advocate for the state. She also lived in Ghana, Africa in 2012 while working as a volunteer teacher at Challenging Heights, a non-profit organization for rescued children. Jodi began working at Southeast Missouri State University in 2013, shortly before beginning the doctoral program. Throughout her doctoral journey, she maintained her Victim Advocacy role and focused much of her work on human trafficking and after care services, the topic she ultimately chose for her dissertation. She also co-wrote two research studies on the topic of campus sexual assaults, the Clery Act, and Title IX with Dr. David Stader, her dissertation advisor.

Jodi married Dustin Cunningham in February, 2016 and started her own photography business later that year. She graduated from the University of Missouri with her doctoral degree in Educational Leadership and Policy Analysis in May, 2017 and plans to continue researching human trafficking, to become more involved with various advocacy and service organizations, and to grow her photography business. She and Dustin are looking forward to starting a family and seeing where this adventure called life takes them next. 